\title{
DETECTION METHOD OF SUBCLINICAL ATHEROSCLEROSIS OF THE CAROTID ARTERY WITH A HEMODYNAMICS MODELING APPROACH
}

\author{
A Thesis \\ presented to \\ the Faculty of California Polytechnic State University, \\ San Luis Obispo
}

\author{
In Partial Fulfillment \\ of the Requirements for the Degree \\ Master of Biomedical Engineering in Blended MS BMED Program
}

by

Marisa Peressini

June 2018 
(C) 2018

Marisa Peressini

ALL RIGHTS RESERVED 
COMMITTEE MEMBERSHIP

TITLE: Detection Method of Subclinical Atherosclerosis of the Carotid Artery with a Hemodynamics Modeling Approach

AUTHOR: $\quad$ Marisa Peressini

DATE SUBMITTED: June 2018

COMMITTEE CHAIR: Michael Whitt, Ph.D. MBA

Professor of Biomedical Engineering

COMMITTEE MEMBER: David Clague, Ph.D.

Professor of Biomedical Engineering

COMMITTEE MEMBER: $\quad$ Pat Senarith, M.S.

Abbott 


\begin{abstract}
Detection Method of Subclinical Atherosclerosis of the Carotid Artery with a Hemodynamics Modeling Approach
\end{abstract}

Subclinical atherosclerosis is an important area of research to evaluate stroke risk and predict localization of plaque. The current methods for detecting atherosclerosis risk are insufficient because it is based on The Framingham Risk Score and carotid intima media thickness, therefore an engineering detection model based on quantifiable data is needed. Laminar and turbulent flow, dictated by Reynolds number and relative roughness, was modeled through the carotid artery bifurcation to compare shear stress and shear rate. Computer-aided design and fluid flow software were used to model hemodynamics through the carotid artery. Data from the model was derived from governing equations programmed in COMSOL for both laminar and turbulent flow. A carotid artery model is accurate enough to describe how relative roughness, flow profiles, and shear rate can be a good prediction of subclinical atherosclerosis.

Keywords: subclinical atherosclerosis, relative roughness, hemodynamics, plaque 


\section{ACKNOWLEDGMENTS}

I would like to thank my thesis advisor Dr. Whitt of the Biomedical Engineering Department at Cal Poly. He always kept my thought process on track and gave me the guidance needed for this thesis.

I would also like to acknowledge Matthew Whitman, Cal Poly Biomedical Engineering student for his help with Fusion 360 modeling. 


\section{TABLE OF CONTENTS}

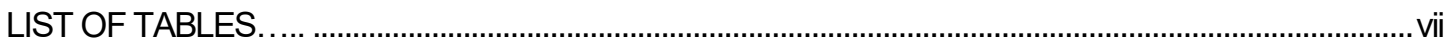

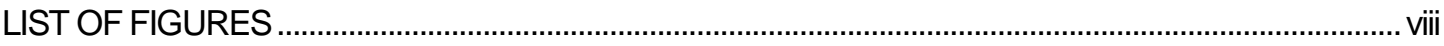

CHAPTER

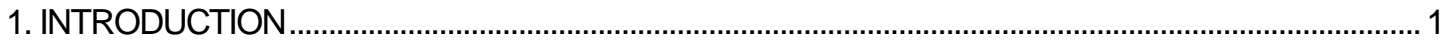

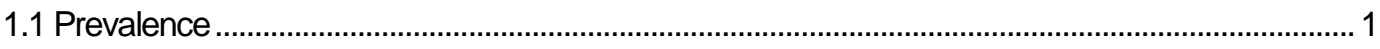

1.2 Framingham Coronary Heart Disease Risk Score ...................................................................... 1

1.3 Carotid Intima Media Thickness ..........................................................................................................

1.4 Endothelial Dysfunction ........................................................................................................ 3

1.5 Plaque ...........................................................................................................................

1.6 The Variability of CIMT and Plaque …………………………………………………….... 4

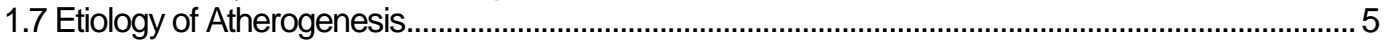

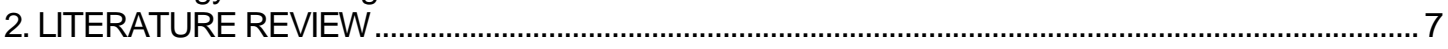

2.1 Wall Shear Stress ............................................................................................................ 7

2.2 Non-Newtonian Blood Properties............................................................................................... 8

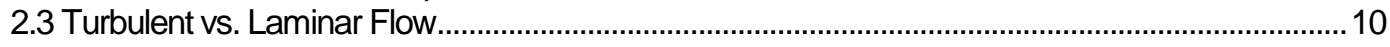

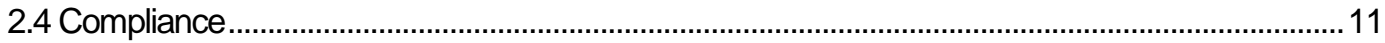

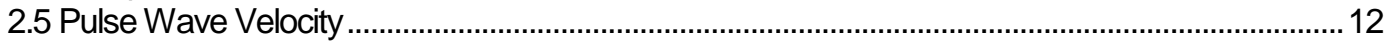

2.6 Relative Roughness, Stenosis, and Friction Factor ......................................................................

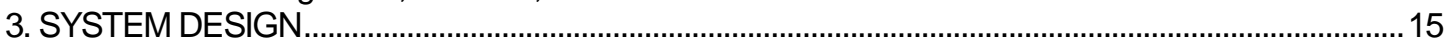

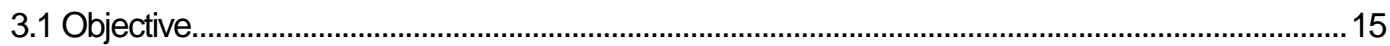

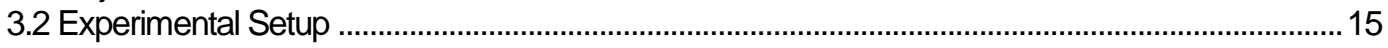

3.3 Software Used ............................................................................................................... 19

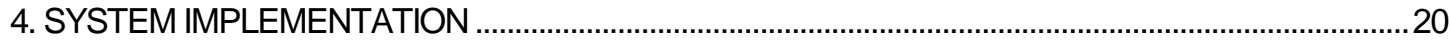

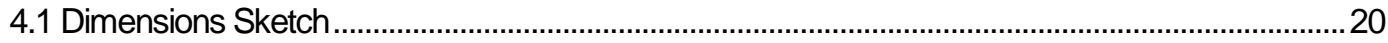

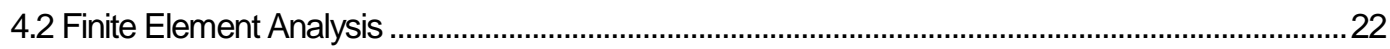

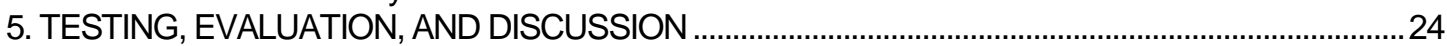

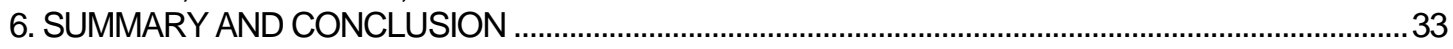

6.1 Contributions of This Work to the Field .................................................................................... 33

6.2 Limitations/Strengths and Weaknesses of This Work ....................................................................33

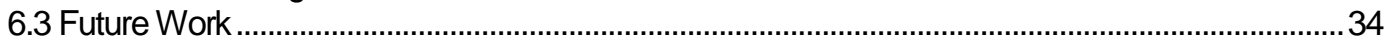

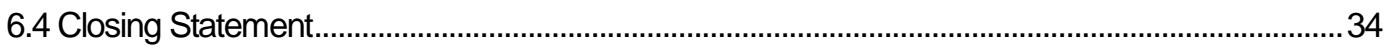

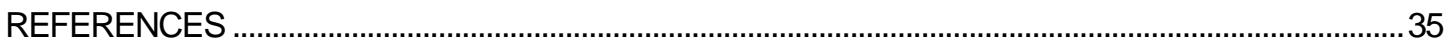

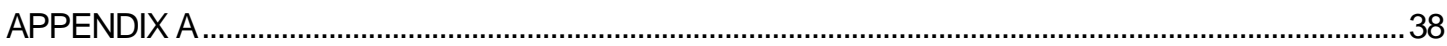

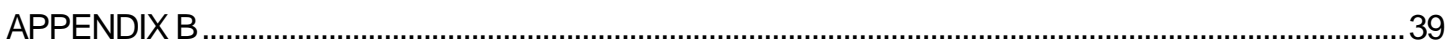




\section{LIST OF TABLES}

Table

Page

1.1 Classification of Recommendations and Level of Evidence Size of Treatment Effect.......................2

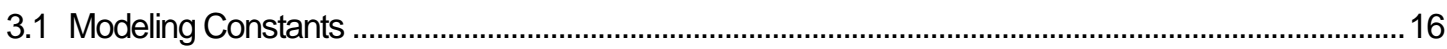

4.1 CCA, ICA, and ECA dimensions adapted for the following model shown in Figure 4.1 ....................20

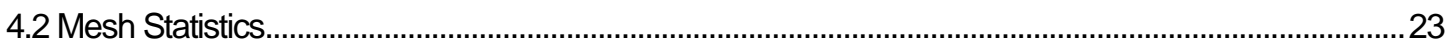

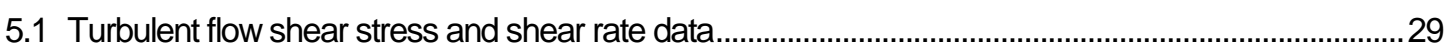

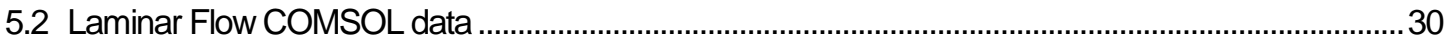

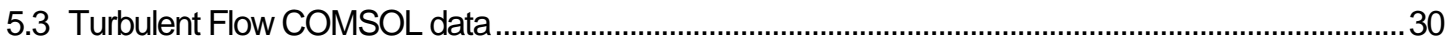

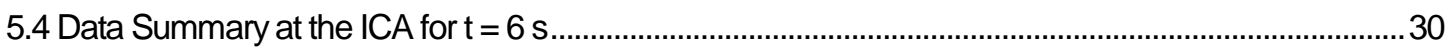

A.1 Friction factor and relative roughness data calculated from previous experiments (see section 2.6) for turbulent flow 


\section{LIST OF FIGURES}

Figure

Figure 1.1: Clinician examination taking CIMT measurements ............................................................. 2

Figure 1.2: Atherogenesis etiology and atherosclerotic plaque pathway ................................................ 6

Figure 2.1: The carotid bifurcation with regions of low and high stress with circulating blood ...................... 7

Figure 2.2: Virchow's Triad illustrating the direct correlation that abnormal blood flow, hypercoagulability, and endothelial injury are key contributors to thrombosis............................................ 8

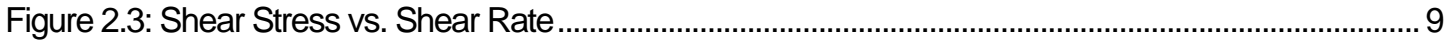

Figure 2.4: Relative viscosity vs. Hematocrit..................................................................................

Figure 2.5: Fully developed flow profile at the CCA, ICA and ECA ........................................................10

Figure 2.6 (A, B): Logan paper relative roughness data A, relative roughness vs. \%stenosis in the aorta with $R^{2}=0.6195$ and $p$-value $=0.000836$. $B$, relative roughness vs. friction factor for lower degree stenosis at $R e=200 . R^{2}=0.8126$ and $p$-value $=0.03659$ with a confidence interval of $95 \%$.

Figure 4.1: SolidWorks drawing including front, side, top, bottom, and orthogonal views of modeled geometry where all dimensions are in millimeters ................................................................................... 21

Figure 4.2: Carotid artery bifurcation 3D geometry represented in COMSOL $\ldots \ldots \ldots \ldots \ldots \ldots \ldots \ldots \ldots \ldots \ldots \ldots \ldots \ldots \ldots . . .22$

Figure 4.3: Finite element analysis using mesh represented. 3D meshed model in COMSOL using an extremely coarse tetrahedral mesh for fluid dynamics.

Figure $5.1(A, B)$ : X-Z sliced profile plots of velocity represented. A) laminar flow ranging from 0-30 $\mathrm{cm} / \mathrm{s} \mathrm{B}$ ) turbulent flow ranging from $0-45 \mathrm{~cm} / \mathrm{s}$.

Figure $5.2(A, B)$ : X-Z sliced profile plots of shear stress represented. A) laminar flow ranging from

0.2-1.6 $\mathrm{Pa} \mathrm{B}$ ) turbulent flow ranging from $0.5-3 \mathrm{~Pa}$

Figure 5.3 $(A, B)$ : X-Z sliced profile plots of shear rate represented. A) laminar flow ranging from $100-500(1 / \mathrm{s}) \mathrm{B})$ turbulent flow ranging from 200-1000 (1/s)

Figure $5.4(A, B)$ : X-Z sliced profile plots of cell Reynolds number represented. A) laminar flow ranging from 0-9 B) turbulent flow ranging from 0-14.

Figure 5.5: Cut points 1 and 3 taken at the carotid bulb wall of the ICA and cut points 2 and 4 taken 
at the centerline of the ICA and ECA respectively ................................................................................2

Figure 5.6: Shear Rate vs. Cell Reynolds Number .................................................................................

Figure 5.7: Viscosity vs. Shear Rate for various hematocrit percentages ...................................................32 
Chapter 1

INTRODUCTION

\section{Prevalence}

Cardiovascular disease (CVD) accounts for 1 out of every 3 deaths in the United States ${ }^{1}$. Specifically, stroke is the leading cause of long-term disability and is the fifth leading cause of death in the US ${ }^{1}$. The incidence of stroke can be attributed to a lack of understanding risk.

\section{Framingham Coronary Heart Disease Risk Score}

Many Americans are unaware of their risk for having a stroke because they have a low Framingham Coronary Heart Disease Risk Score (FRS). FRS assigns a risk probability for a 10year period based on dyslipidemia, age, sex, hypertension, smoking, low (LDL) and high (HDL) density lipoprotein cholesterol and blood pressure ${ }^{2}$. Some limitations include that FRS is not specific in predicting which Major Adverse Cardiovascular Event (MACE) will occur and it was defined only using data from the US population. The original FRS was published in 1998 and the current FRS was published in 2008.

\section{Carotid Intima Media Thickness}

Another common method to measure stroke risk is carotid intima media thickness (CIMT). Early studies aimed to find a better indicator for subclinical atherosclerosis and found that CIMT can yield quantitative results ${ }^{3,4}$. The CIMT measurement is usually observed via B-mode ultrasound imaging and sensitive edge-detection software. CIMT is measured between the intimal luminal and the medial-adventitial interfaces of the carotid artery wall represented as a double-line density on an ultrasound image ${ }^{5}$. Patients can view their real-time CIMT and plaque measurements during outpatient cardiology practices to educate, treat, and take action to prevent $\mathrm{CVD}^{3}$. These real-time measurements are provided as a percentage relative to age, gender, and race so that patients can compare their risk to another patient's risk. 


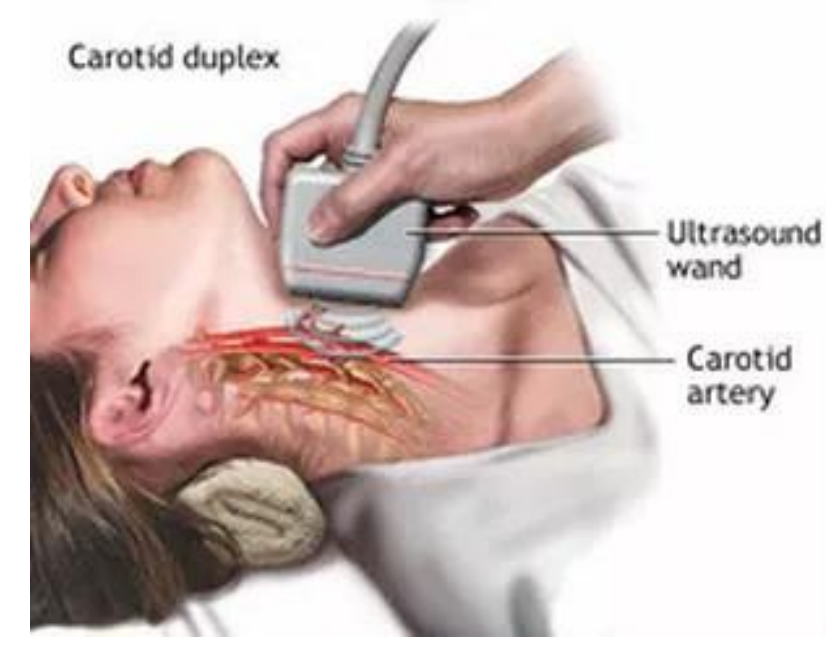

Figure 1.1: Clinician examination taking CIMT measurements

However as of 2013, Intima Media Thickness (IMT) measurements were deemed a class III indicator because of variability in measurement data. ${ }^{6}$ The following indications for therapy intervention are shown below ${ }^{31}$.

Table 1.1 Classification of Recommendations and Level of Evidence Size of Treatment Effect

\begin{tabular}{|l|l|}
\hline Class I & $\begin{array}{l}\text { Conditions for which there is evidence and/or } \\
\text { general agreement that a given procedure or } \\
\text { treatment is beneficial, useful, and effective }\end{array}$ \\
\hline Class II & $\begin{array}{l}\text { Conditions for which there is conflicting } \\
\text { evidence and/or a divergence of opinion about } \\
\text { the usefulness/efficacy of a procedure or } \\
\text { treatment }\end{array}$ \\
\hline Class III & $\begin{array}{l}\text { Conditions for which there is evidence and/or } \\
\text { general agreement that a procedure/treatment } \\
\text { is not useful/effective and in some cases may } \\
\text { be harmful }\end{array}$ \\
\hline
\end{tabular}

IMT is dependent on sensitive imaging software therefore variability in measurements is difficult to establish standards to categorize subclinical atherosclerosis risk. Because of its variability, there are no national screening guidelines for subclinical atherosclerosis ${ }^{7}$. IMT measurement may still be used, however, it is recommended to be used in combination with $\mathrm{FRS}^{2}$ to increase sensitivity. 


\section{Endothelial Dysfunction}

Endothelial dysfunction (ED) with CIMT data may yield a more accurate indication of subclinical atherosclerosis $8,9,10,11$. The endothelium is the inner lining of blood vessels and serves as a defense system against CVD. The endothelium provides a healthy balance between a thrombotic, and non-thrombotic environment that allows for normal blood flow. If the endothelium is promoting a hypercoaguable state, blood flow may be disrupted, causing the possibility of a thrombus or thromboemboli. ED is the reduction of the bioavailability of vasodilators, particularly nitric oxide (NO), and/or an increase in endothelium-derived contracting factors ${ }^{12}$. As a results of ED, vasodilation is inhibited therefore velocity increases. ED on a broader spectrum, is known to initiate subclinical atherosclerosis because it responds to increased shear stress, pressure, and pulsatility.

The importance of understanding endothelial dysfunction is that ED is the most significant predictor of $\mathrm{MACE}^{32}$. A patient can detect negative for elevated LDL levels that would not support an atherosclerotic state, but still have a stroke because of inflammation associated ED. Endothelial cells can also undergo physical changes that cause a decrease in NO release, promoting vasoconstriction, inflammation, and thrombosis. ED was added to the FRS because it is predictive beyond traditional risk scoring in elderly patients and post-menopausal women ${ }^{29}$.

\section{Plaque}

Another factor with a possible significant effect on endothelial dysfunction is plaque. A study evaluated the relationship among Body Mass Index (BMI), carotid sonographic findings, and longterm Cardiovascular (CV) events in Asian patients with $C A D^{22}$. They found that $B M I$ is negatively associated with CV events in patients with CAD, which is otherwise known as the obesity paradox. They found that underweight and normal-weight patients were more likely to have carotid plaque, therefore leading to the possibility that plaque can earlier predict subclinical atherosclerosis than CIMT.

On the other hand, CIMT and plaque analysis were performed by 2 trained medical residents on 60 patients to attempt to validate replicable testing. With 13 hours of training, there was only $53 \%$ 
plaque data agreement and $88 \%$ CIMT data agreement between trained medical residents and professionals ${ }^{23}$. This counters the previous study that plaque is a better measurement than CIMT data for detection of subclinical atherosclerosis, and therefore needs further examination.

Nonobstructive plaque is the focal thickening of at least $50 \%$ greater than that of the surrounding vessel wall ${ }^{24}$. Plaque is much less common in the common carotid artery because blood flow is laminar, therefore it cannot be detected by Doppler techniques. Since plaque has a 3D nature, it can be characterized by plaque number, thickness, area, volume, and vascularity 5 instead of thickness alone where plaque area is measured as the sum of all cross-sectional areas in a longitudinal view and plaque number is a countable measure of plaque in a particular region. Plaque morphology and composition complexity allow many variables to evaluate in determining implications for CV risk.

It is of interest to observe plaque development at its earlier stages to earlier detect subclinical atherosclerosis. It is not as valuable to know the degree of stenosis as it is to know the likelihood of plaque becoming vulnerable to cause stroke. Unlike CIMT, carotid plaque represents predominantly intimal thickening with foam cells, smooth muscle cells, macrophages, lipid core, and fibrous cap depending on the stage of plaque development. Carotid plaque is therefore a measurement that illustrates all stages of atherogenesis.

\section{The Variability of CIMT and Plaque}

Depending on the study, plaque can either be included or excluded in the CIMT measurement. Some studies purposely took a CIMT measurement in a region with no plaque which can misclassify stroke risk ${ }^{4-7}$. There is a lack of consensus amongst IMT professionals regarding how plaque is defined. Some studies describe plaque as a $1 \mathrm{~mm}$ protrusion into the intima, while other studies classify plaque as a $1.2 \mathrm{~mm}$ protrusion. The definition of plaque would not be a problem if the data were normalized against a standard deviation, however this is not always the case. Some studies only report plaque as purely 'yes' it exists, or 'no' it does not exist. This could interfere with the accuracy in diagnosing risk for stroke and for quantifying subclinical atherosclerosis. 
Plaque can potentially be a better measurement for monitoring the progression or regression of diseased carotid arteries than IMT measurements. There is only a 10-40 microns change in IMT for both healthy and diseased patients annually, which can be difficult for b-mode ultrasound to detect subtle changes. Multiple check-ups may be required of the patient to monitor IMT status. Plaque not only progresses in thickness, but in morphology, geometry, and vascularity. Plaque can change $10 \mathrm{~mm}^{2}$ annually, therefore yielding a more sensitive analysis than IMT and patients can check their progress regularly. Observing multifaceted plaque could better describe the progression or regression of atherosclerosis than IMT, especially when data is collected in an Imaging Core Lab (ICL). An ICL needs to meet FDA requirements to upkeep quality, therefore plaque measurement data is held to FDA standards.

\section{Etiology of Atherogenesis}

An early event in atherosclerosis is characterized by heightened lipid and protein oxidation in the vascular wall3-5. Plaque formation is a positive feedback loop initiated by endothelial dysfunction. Oxidized LDL are the most atherogenic forms of LDL and is a potent inducer of inflammatory molecules ${ }^{4}$. Lipoprotein lipase converts very low-density lipoprotein (vLDL) into LDL by removing triglycerides to release free fatty acids. LDL is transported out of the lumen and through the endothelium to become trapped in the extracellular matrix (ECM). LDL is oxidized via Sphingomyelinase, Secretory Phospholipase-2, and myeloperoxidase enzymes. Ox-LDL triggers the release of chemotactic proteins that attract monocytes into the arterial wall. Monocytes are differentiated into macrophages after they have traveled through the endothelium and into the ECM. Macrophages uptake oxLDL to differentiate the molecules into foam cells; atherosclerotic plaque is now initiated. OxLDL promote endothelial dysfunction by reducing vasodilators such as NO. Nitric oxide synthase is inhibited by oxLDL which inhibits the production of NO, an important molecule in regulating arterial blood pressure.

Along with atherosclerotic plaque, the mechanical properties of macrophages could influence ED. Mechanical properties such as membrane bending modulus and effective cell viscosity allow macrophages to have unique surface properties ${ }^{30}$ that come in contact with the lumen of the artery. Activated macrophages also release cytokines such as tumor necrosis factor (TNF), 
interleukin-1 (IL-1), and interleukin-6 (IL-6) that activate the endothelin-1 (ET-1) pathway.

Cytokines cause endothelial cells to release ET-1, which binds to vascular smooth muscle cells (SMCs) and fibroblasts. The end results of this signaling cascade are cell contraction, migration, proliferation, and fibrosis. Ultimately, intimal thickening occurs in SMCs that causes stenosis of arteries.

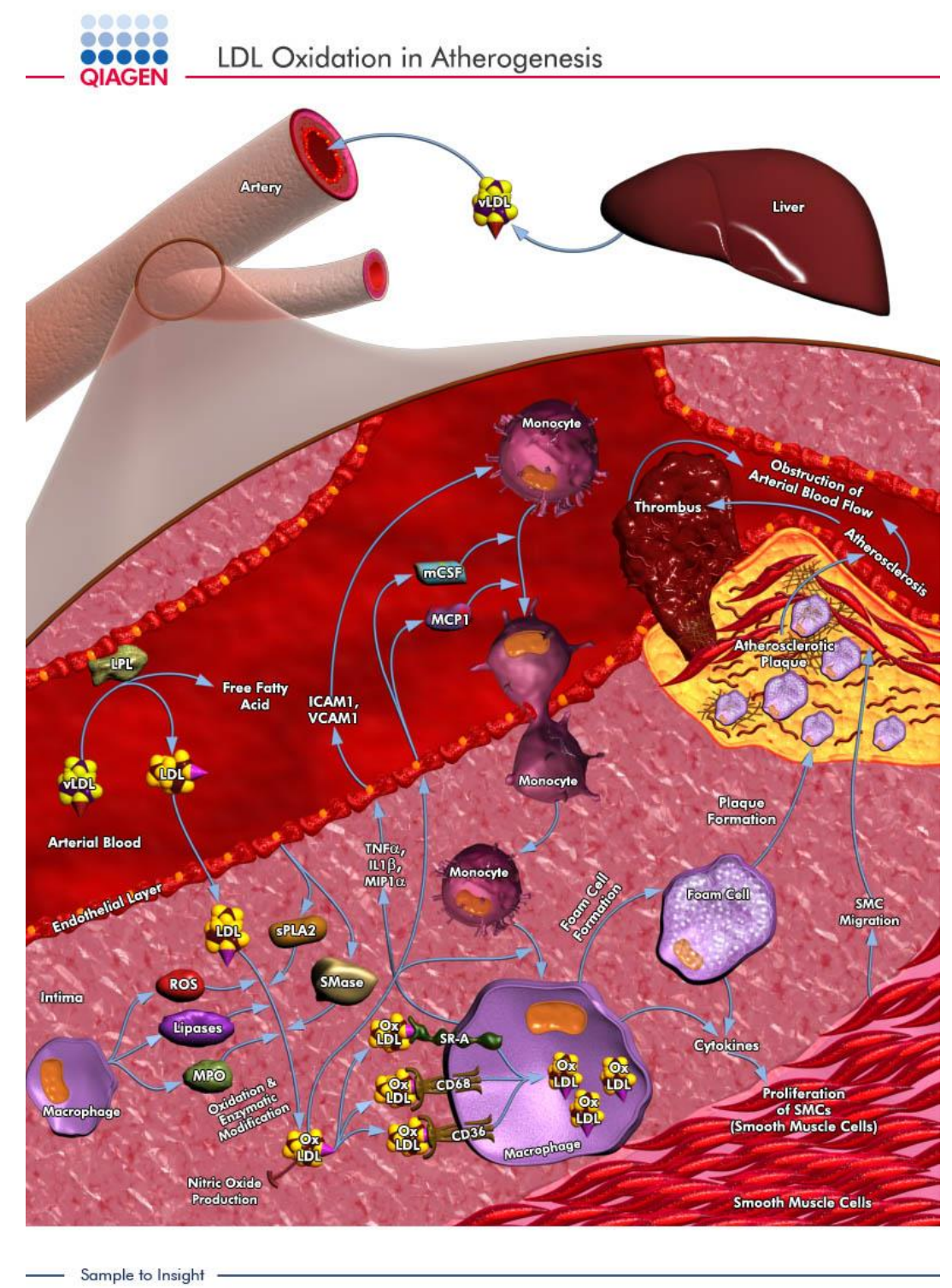

(C) 2009 QIAGEN, all rights reserved

Figure 1.2: Atherogenesis etiology and atherosclerotic plaque pathway ${ }^{36}$ 
Chapter 2

\section{LITERATURE REVIEW}

\section{Wall Shear Stress}

Atherosclerosis tends to form at the carotid bulb ${ }^{5}$, particularly towards the outer wall where the shear stresses are low and oscillations in shear stresses are high $5,14,15$. The lack of vasodilation from the lack NO results in a decrease of blood flow, and therefore a decrease in shear stress.

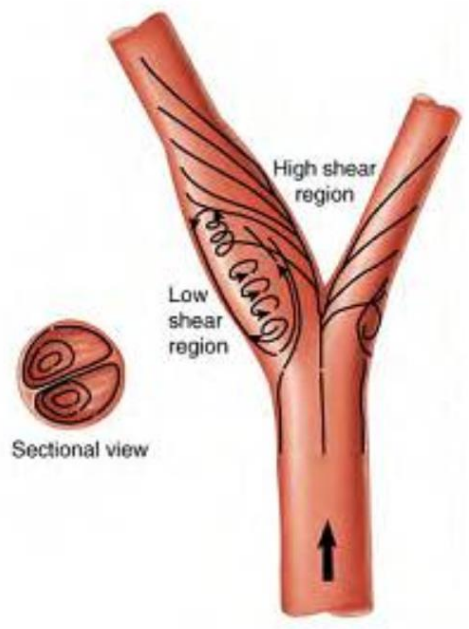

Figure 2.1: The carotid bifurcation with regions of low and high stress with circulating blood

Hemodynamics through the carotid artery is valuable to observe because endothelial cells behave differently under high and low shear stress environments ${ }^{16}$. Under non-atherosclerotic conditions, flow is typically laminar which keeps Endothelial Cells (ECs) athero-protective. However, turbulent flow regions such as the bifurcation of the carotid artery are susceptible to atherogenesis because turbulent flow can cause endothelial injury. This phenomenon is explained by Virchow's Triad in Figure 2.1. Virchow's triad was named after Rudolf Virchow, a physician of the 1800 s, to better understand the factors that contribute to thrombosis and is still used today by physicians and scientists. The bifurcation geometry naturally allows stasis, or blood pooling. Stasis encourages a pro-atherosclerotic environment because of leukocyte and thrombotic protein exposure to the endothelium. Abnormal blood flow can also prevent dilution of 
activated clotting factors by fresh-flowing blood, disrupt clotting factor inhibitor flow, and promote endothelial cell activation ${ }^{25}$.

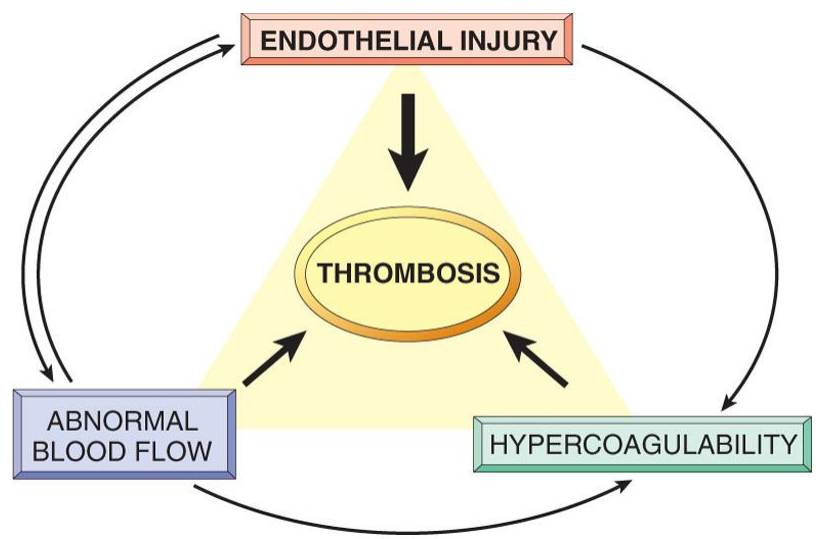

Figure 2.2: Virchow's Triad illustrating the direct correlation that abnormal blood flow, hypercoagulability, and endothelial injury are key contributors to thrombosis.

An early study tested the hypothesis that the common carotid artery wall shear stress measurement in vivo is reproducible and concluded that the shear stress is inversely related to the intima-media thickness, age, systolic blood pressure, and $\mathrm{BMI}{ }^{16}$ for healthy endothelium. Shear stress can be a valuable metric because it is inversely correlated with both endothelial dysfunction and CIMT.

Shear stress can be described as Newton's viscosity equation:

$$
\tau=-\mu \frac{\partial u}{\partial y}
$$

where $\mu$ is the viscosity $\left(\mathrm{Ns} / \mathrm{m}^{2}\right), \mathrm{u}$ is the velocity $(\mathrm{m} / \mathrm{s})$, and $\mathrm{y}$ is the distance from the surface (m).

\section{Non-Newtonian Blood Properties}

The non-Newtonian property of blood, however, inhibits the ability to use Newton's law of viscosity. Non-Newtonian fluids, otherwise known as viscoelastic fluids, exhibit both viscous and 
elastic properties when undergoing deformation. There is no longer a linear relationship between shearing stress and strain.

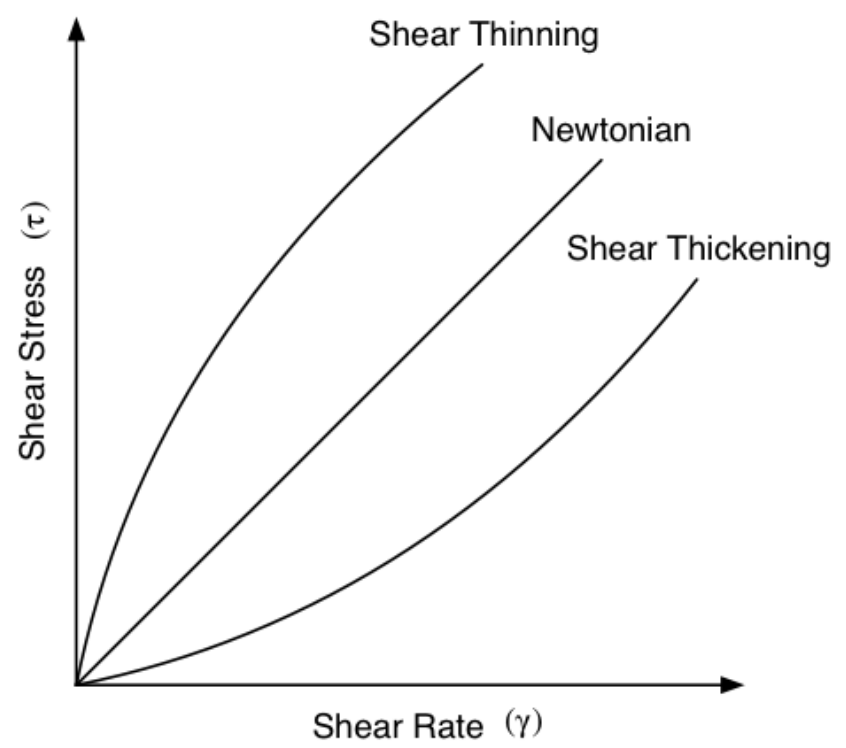

Figure 2.3: Shear Stress vs. Shear Rate ${ }^{33}$

Blood is classified as a shear-thinning fluid because viscosity decreases with shear rate. It is important to take note of the shear-thinning property of blood because fluid flow is highly dependent on the viscosity of the fluid.

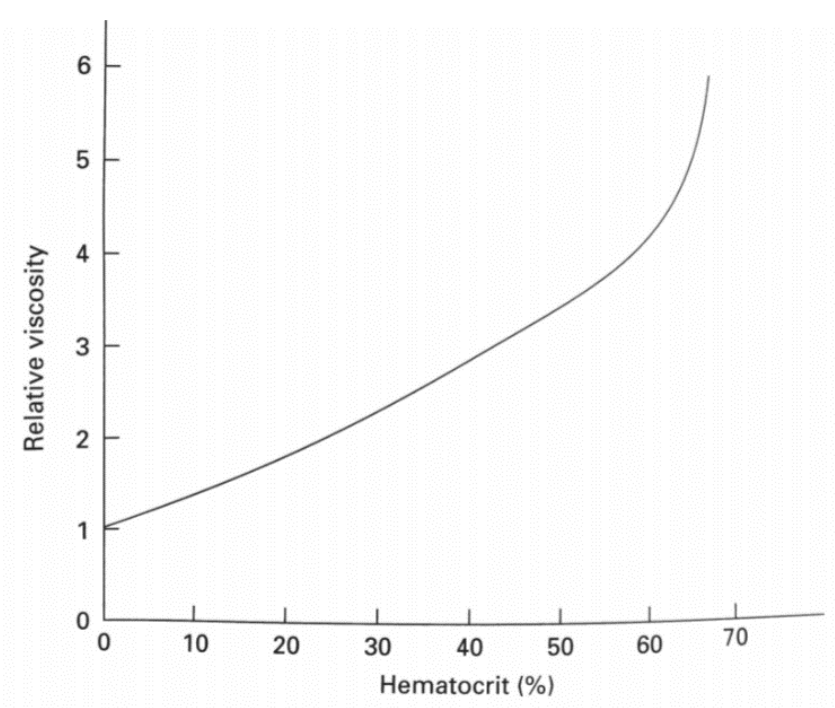

Figure 2.4: Relative viscosity vs. Hematocrit ${ }^{33}$ 
For hematocrit levels from $0-50 \%$, relative viscosity increases as hematocrit increases. Once the hematocrit gets to $60 \%$, viscosity increases exponentially. Even though blood is non-Newtonian, a constant viscosity of $3 \mathrm{cP}$ is assumed because a normal hematocrit value of $44.5 \%$ is assumed.

\section{Turbulent vs Laminar Flow}

Turbulent flow exists through a cylindrical smooth pipe for Reynolds numbers greater than 2600 , laminar flow for Reynolds numbers less than 2300, and transitional flow for Reynolds numbers in between 2300-2600. With turbulent flow, there are circulating currents known as eddies that transfer mass and momentum to neighboring flows that creates a domino effect increasing turbulent flow. Therefore, turbulent flow can be related to higher values of friction ${ }^{28}$. Regions of turbulent flow are commonly found at the carotid artery bifurcation and the internal carotid artery (ICA) sinus due to the geometrical shape but could also occur from increased friction.

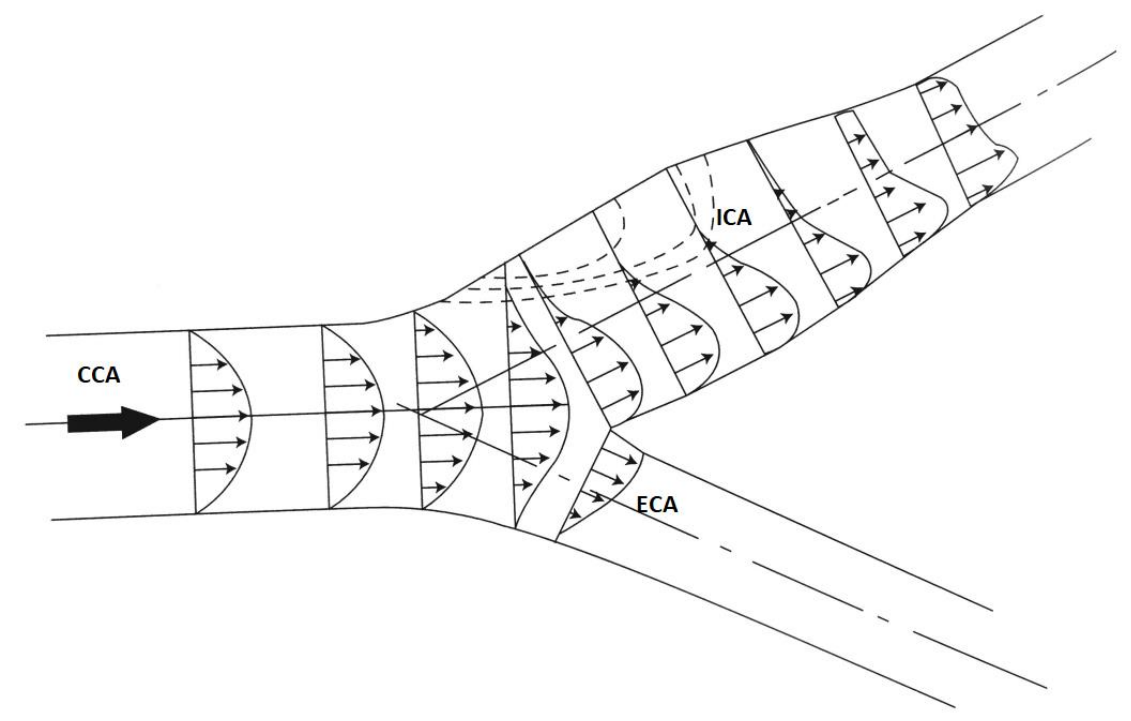

Figure 2.5: Fully developed flow profile at the Common Carotid Artery (CCA), Internal Carotid Artery (ICA), and External Carotid Artery (ECA) ${ }^{33}$

There is an indirect relationship between friction factor and Reynolds number for laminar flow:

$$
f=\frac{64}{R e}
$$


The friction factor for turbulent flow through the carotid artery, on the other hand, is quite complicated. There are approximations that can be calculated for turbulent flow friction factor dependent on Reynolds number range, smoothness or roughness, free surface flow, and hydraulic radius. The Blasius equation ${ }^{37}$ is an approximation for turbulent friction factor for nonNewtonian fluids:

$$
f=\frac{2 \tau_{w}}{\rho u^{2}}=\frac{0.079}{R e^{1 / 4}}
$$

where $\tau_{w}$ is the wall shear stress $(\mathrm{Pa}), \rho$ is the fluid density $\left(\mathrm{kg} / \mathrm{m}^{3}\right)$, and $u$ is the velocity $(\mathrm{m} / \mathrm{s})$

The turbulent friction factor can either be mathematically calculated with the Blasius equation, or calculated from experimental data. For large arteries with surface roughness but no stenosis, $R e$ values for turbulent flow are in the $400-500$ range $^{26,33}$. For large arteries with surface roughness and stenosis, Re values for laminar flow are approximately $200^{26,33}$. This suggests that turbulent flow dominates in arteries where surface roughness is more important than the \% stenosis.

\section{Compliance}

Arterial compliance is the index of the elasticity of the vessels. Langewouters work found a direct correlation among, age, gender, and mean arterial pressure (MAP) with respect to compliance. The compliance of the artery can be mathematically described by the Langewouters equation ${ }^{17}$

$$
C(P)=L \cdot \frac{\frac{A_{\max }}{\pi P_{1}}}{1+\left(\frac{P-P_{0}}{P_{1}}\right)^{2}}
$$

where $A_{\max }$ is the max cross-sectional area $\left(\mathrm{m}^{2}\right), P_{0}$ is the pressure at which compliance reaches a maximum $(\mathrm{Pa}), \mathrm{L}$ is the vessel length $(\mathrm{m})$, and $P_{1}$ is the width of the compliance curve at half of the maximum compliance $(\mathrm{Pa})$. Compliance contributes to the arteries ability to dilate and contract in response to sympathetic nervous system (SNS) or parasympathetic nervous system (PNS) stimulation. Therefore, a healthy artery will have a higher compliance than a diseased artery. 


\section{Pulse Wave Velocity}

Carotid-femoral pulse wave velocity is the gold standard measurement of arterial stiffness ${ }^{18}$. The measurement is accepted because it is non-invasive and reproducible. Endothelial function is inversely related to $\mathrm{PWV}^{19}$, and can be estimated mathematically. PWV can be measured either as a regional measurement (between two vessels) or a local measurement, however, a local measurement has been shown to be more precise ${ }^{20}$. PWV can be estimated via the MoensKorteweg equation:

$$
P W V=\sqrt{\frac{h E_{i n c}}{2 r \rho}}
$$

where $E_{i n c}$ is the incremental elastic modulus of the vessel wall $(\mathrm{Pa}), \mathrm{h}$ is the wall thickness $(\mathrm{m}), \mathrm{r}$ is the vessel radius $(\mathrm{m})$, and $\rho$ is the density of blood $\left(\mathrm{kg} / \mathrm{m}^{3}\right)$.

The Moens-Korteweg equation, however, is only valid for inviscid, incompressible flow therefore is not the best estimation for viscous blood flow.

The Bramwell and Hill model ${ }^{21}$ used the Moens-Korteweg equation to approximate wave speed as a function of the inverse of compliance, referred as distensibility. A doppler flow meter can be implemented in an in vitro model to find pressure changes.

The Bramwell and Hill model can be described using the following equation:

$$
P W V=\sqrt{\frac{V d P}{\rho d V}}
$$

PWV occurs in the large arteries of the systemic circulatory system, and may vary depending on age and hypertension; both factors included in $\mathrm{FRS}^{33}$.

\section{Relative Roughness, Stenosis, and Friction Factor}

The exact relationship between resistance and geometry of arterial vessels are not well described. A hemodynamics study conducted on postmortem stenotic human coronary arteries aimed to better define quantitative relationships of stenotic geometry, perfusion pressure, flow rate, and coronary resistance ${ }^{26}$. The three parameters measured were the degree of stenosis, coronary autoregulation, and coronary perfusion pressure where coronary autoregulation is the 
ability of the coronary arteries to maintain a constant blood flow despite changes in coronary perfusion pressure. The results indicated that rougher arteries had a lower volumetric flow rate, which can be important in detection of MACE. Subclinical atherosclerosis develops in the early stages where range of stenosis is low, therefore relative roughness could be used as a qualitative measure because of its normalized value.

The data collected from the study was graphed to determine a relationship between the degree of stenosis and relative roughness with $n=14$. Another relationship is suggested between relative roughness and friction factor with $n=5$. With an $R^{2}$ value of 0.6195 and $p=0.000836$, the data suggests that relative roughness is the main contributor to $\%$ stenosis at $95 \%$ confidence. Likewise, with an $R^{2}$ value of 0.8126 and $p=0.03659$, relative roughness is the main contributor to friction factor at $95 \%$ confidence, therefore relative roughness is an important metric to evaluate. 

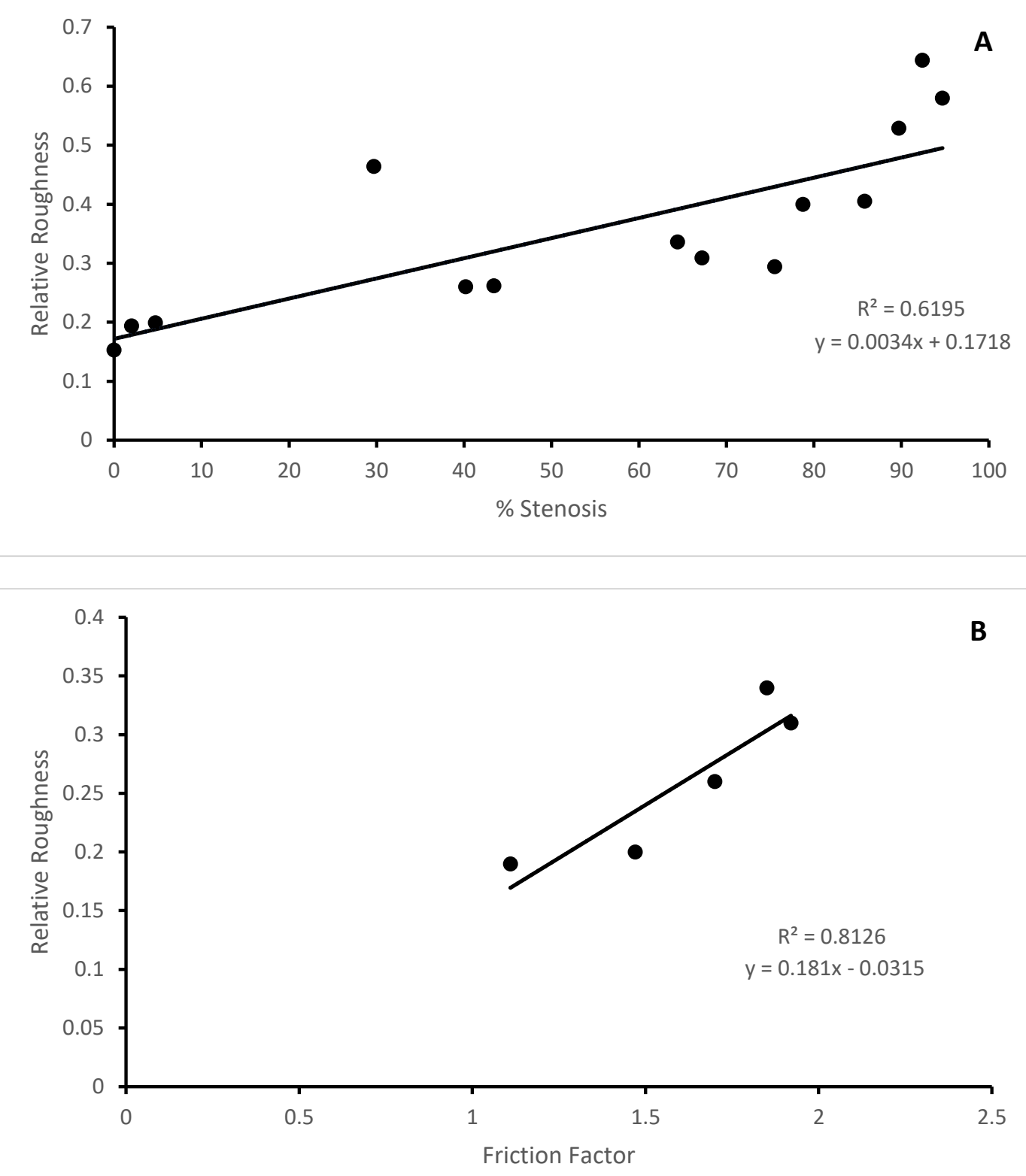

Figure 2.6 (A, B): Logan paper relative roughness data A, relative roughness vs. \%stenosis in the aorta with $R^{2}=0.6195$ and $\mathrm{p}$-value $=0.000836$. $\mathrm{B}$, relative roughness vs. friction factor for lower degree stenosis at $\mathrm{Re}=200 . R^{2}=0.8126$ and $\mathrm{p}$-value $=0.03659$ with a confidence interval of $95 \%$.

Using the relative roughness and friction factor relationship data from Figure $2.5 \mathrm{~B}$, an average friction factor for turbulent flow is approximately 1.61 and the average relative roughness is 0.26 . 
Chapter 3

\section{SYSTEM DESIGN}

\section{Objective}

The purpose of this paper is to address the question of where subclinical atherosclerosis originates. I am proposing the solution that increased shear rate in the arterial wall as a result from endothelial dysfunction upregulates inflammation, relative roughness, and disrupts the flow profile of blood. The transition of laminar to turbulent flow causes plaque development that creates a positive feedback loop of increased shear rate and inflammation. The goal is to understand the initial stimulus of subclinical atherosclerosis to inhibit further progression of the disease.

With Reynolds number being a function of friction factor, and with friction factor being a function of relative roughness, the type of flow corresponds to relative roughness. The type of flow (laminar or turbulent) is a dependent variable that corresponds to varying Reynolds numbers. As a response, endothelial dysfunction is caused by an increase in shear rate, which is caused by disruption to the flow profile. Ultimately, disturbances of the flow profile are caused by the relative roughness of the endothelium. There is not a consensus regarding the root cause of differences between relative roughness in arteries, and why some people are more prone to having "rougher" arteries than others. The emphasis of this investigation includes using hemodynamics to observe shear rate and friction factor at the carotid bifurcation, the most likely region of plaque.

\section{Experimental Setup}

A 3D model of the carotid artery was constructed in Fushion 360, edited in SolidWorks, and then imported into COMSOL. The carotid artery geometry includes the $y$-shaped bifurcation of the internal (ICA) and external (ECA) carotid arteries, and the common carotid artery (CCA). Shear stress, shear rate, and relative Reynolds number were measured in the COMSOL model. For accurate computational analysis, the mesh was specific to fluid dynamics. 
Table 3.1 Modeling constants

\begin{tabular}{|c|c|}
\hline & Constants \\
\hline Viscosity $(\boldsymbol{\mu})$ & $3 \mathrm{cP}$ \\
\hline Density of Blood $(\boldsymbol{\rho})$ & $1060 \frac{\mathrm{kg}}{\mathrm{m}^{3}}$ \\
\hline Frequency (f) & $601 / \mathrm{min}$ \\
\hline Phi $^{\boldsymbol{*}}(\boldsymbol{\varphi})$ & 0.5 \\
\hline Turbulent velocity & $80 \mathrm{~cm} / \mathrm{s}$ \\
\hline Laminar velocity & $40 \mathrm{~cm} / \mathrm{s}$ \\
\hline
\end{tabular}

${ }^{*} \varphi=0.5$ is an approximation derived from the Womersley Equation ${ }^{33}$ to approximate the volumetric pulsatile velocity profile in phase lag form

Assumptions:

1. Newtonian fluid

2. Time-dependent, pulsatile flow

3. No slip boundaries at wall $(u=0)$

Governing equations:

To describe the motion of viscous flow, COMSOL uses the Navier-Stokes equation for computational fluid dynamics.

1. Navier-Stokes

$$
\rho \frac{\partial u}{\partial t}+\rho u \nabla u=-\nabla P+\mu \nabla^{2}+F
$$

where $\rho$ is density $\left(\mathrm{kg} / \mathrm{m}^{3}\right), u$ is velocity $(\mathrm{m} / \mathrm{s}), \mu$ is viscosity $\left(\mathrm{Ns} / \mathrm{m}^{2}\right), P$ is pressure $(\mathrm{Pa})$, and $\mathrm{F}$ is external forces applied to the fluid $(\mathrm{N})$.

Newton's viscosity equation from 2.1 can be simplified to 3.2 by including pressure drop between the inlet and outlet.

2. Shear Stress

$$
\tau=-\mu \frac{\partial u}{\partial y}=\frac{h \Delta P}{L}
$$


where $u$ is velocity $(\mathrm{m} / \mathrm{s}), \mu$ is viscosity $\left(\mathrm{Ns} / \mathrm{m}^{2}\right), y$ is the distance from the surface $(\mathrm{m}), \mathrm{h}$ is height i.e. wall to first boundary layer $(m), \Delta P$ is pressure drop from inlet to outlet $(\mathrm{Pa})$, and $L$ is length of the artery $(m)$.

By dropping the viscosity term from Newton's viscosity equation, the shear rate can be calculated using the following:

3. Shear Rate

$$
\gamma=\frac{\partial u}{\partial y}
$$

where $u$ is velocity $(\mathrm{m} / \mathrm{s})$ and $y$ is the distance from the surface $(\mathrm{m})$.

4. Reynolds Number

$$
\mathrm{Re}=\frac{\rho u L_{\mu}}{\mu}=\frac{\text { inertial forces }}{\text { viscous forces }}
$$

where $\rho$ is density $\left(\mathrm{kg} / \mathrm{m}^{3}\right)$, $u$ is velocity $(\mathrm{m} / \mathrm{s}), L_{\mu}$ is the characteristic viscous length scale for internal flow $(\mathrm{m})$, and $\mu$ is viscosity $\left(\mathrm{Ns} / \mathrm{m}^{2}\right)$.

Traditionally, Reynolds number describes a dimensionless relationship between inertial forces to viscous forces which determines the degree of laminar or turbulent flow. Through order of magnitude analysis, Whitatker ${ }^{27}$ modifies Reynolds number by multiplying the standard Re given in Eq. 3.4 above by the ratio of the viscous length scale to the inertial length scale

$$
\frac{L_{\mu}}{L_{\rho}} R e<1
$$

where $L_{\rho}$ is the characteristic length scale of an undisturbed streamline $(m)$. As a consequence, the realized Reynolds number for a cylinder with surface roughness can be much higher than the Reynolds number given in Eq. 3.4, i.e., the ratio in a rough cylinder could result in. In contrast for a perfectly smooth cylinder, the adjusted Reynolds number can be much smaller than as predicted in Eq. 3.4. Qualitatively, this corroborates the Reynolds numbers reported from the experimental findings for large arteries with surface roughness, as discussed in Chapter 2 above. It should be noted that in COMSOL Multiphysics ${ }^{\circledR}$, the software calculates an un-modified "cell" Reynolds number in accordance with Eq. 3.4 but using the specific element or "cell" dimension. 


\section{Womersley Number}

The Womersley number is a dimensionless number in hemodynamics of pulsatile flow frequency. Womersley number is useful in understanding the relationship between transient inertial force and viscous force for arterial experimental studies.

$$
\alpha=r \sqrt{\frac{\omega \rho}{\mu}}
$$

where $r$ is radius of the artery $(m), \omega$ is angular frequency $(2 \pi f)$ where $f$ is the heart rate, $\rho$ is blood density $\left(\mathrm{kg} / \mathrm{m}^{3}\right)$, and $\mu$ is blood viscosity $\left(\mathrm{Ns} / \mathrm{m}^{2}\right)$

\section{Pressure Differences}

Fluid flow will travel from areas of high pressure to areas of low pressure. To initiate flow, laminar and turbulent flow pressure differences are specified at the inlet and outlet using

$$
\Delta P=\frac{8 u \mu L_{\mu}}{r^{2}}
$$

where $\Delta P$ is the pressure drop between inlet and outlet $(\mathrm{Pa}), \mathrm{u}$ is velocity $(\mathrm{m} / \mathrm{s}), \mu$ is viscosity

$\left(\mathrm{Ns} / \mathrm{m}^{2}\right), L_{\mu}$ is the length over which the pressure drop occurs $(\mathrm{m})$, and $\mathrm{r}$ is the average radius of the external carotid artery $(\mathrm{m})$.

\section{Pulsatile Flow}

To represent the pulsatile nature of hemodynamics, the following approximation was used

$$
\text { wave }_{\text {form }}=1+\varphi \sin (\omega t)
$$

where $\varphi=0.5, \mathrm{t}=$ time $(\mathrm{sec})$, and $\omega=2 \pi f$. wave $_{\text {form }}$ mimics the transient nature of pulsatile and time-dependent blood flow.

Combining equations (3.5) and (3.6), the inlet gauge pressure for laminar and turbulent flow at the CCA is

$$
P_{\text {inlet }(u)}=\Delta \text { Pwave }_{\text {form }}
$$


where $P_{\text {inlet }}(\mathrm{u})$ is a function of the velocities given in table 3.1. The outlet pressures for the ECA and ICA are 0.

\section{Software Used}

COMSOL Multiphysics ${ }^{\circledR}$ Version 5.3 was the primary software application used to acquire data. Version 5.3 is the newest version and was available through the Cal Poly Biomedical Engineering Department. COMSOL Multiphysics performs finite element analysis and allows for computational physics-based user interfaces. The software specializes in fluid dynamics applications which was

of interest to answer research questions. It is compatible with importing external CAD models for computation.

Autodesk Fusion 360 was used to create the CAD model of the carotid artery. This software is useful in creating biological models to capture the curves and edges to better replicate the true geometry of the artery.

SOLIDWORKS 2017 was the software medium used to edit the CAD model of the carotid artery. The version used is the newest version and was available through the Cal Poly Biomedical Engineering Department. SOLIDWORKS is the primary CAD modeling software used by biomedical engineers because of its user-friendly interface and 3D modeling capabilities. Microsoft Excel 2016 was used to analyze and graph data for different engineering metrics. 
Chapter 4

\section{SYSTEM IMPLEMENTATION}

\section{Dimensions Sketch}

The following dimensions were adapted from clinical trials ${ }^{38}$ and molding procedures ${ }^{39}$ from the carotid artery to create a 3D model. There is a dimensional range for the CCA and ICA diameter data because these results are derived from both male and female patients for the left and right carotid arteries.

Table 4.1 CCA, ICA, and ECA dimensions adapted for the following model shown in Figure 4.1

\begin{tabular}{|c|c|}
\hline & Dimension (mm) \\
\hline CCA diameter & $5.3-7.5$ \\
\hline CCA length & 38 \\
\hline ICA diameter & $3.88-5.98$ \\
\hline ICA length & 17 \\
\hline ECA diameter & 3.6 \\
\hline Overall length & 55 \\
\hline
\end{tabular}



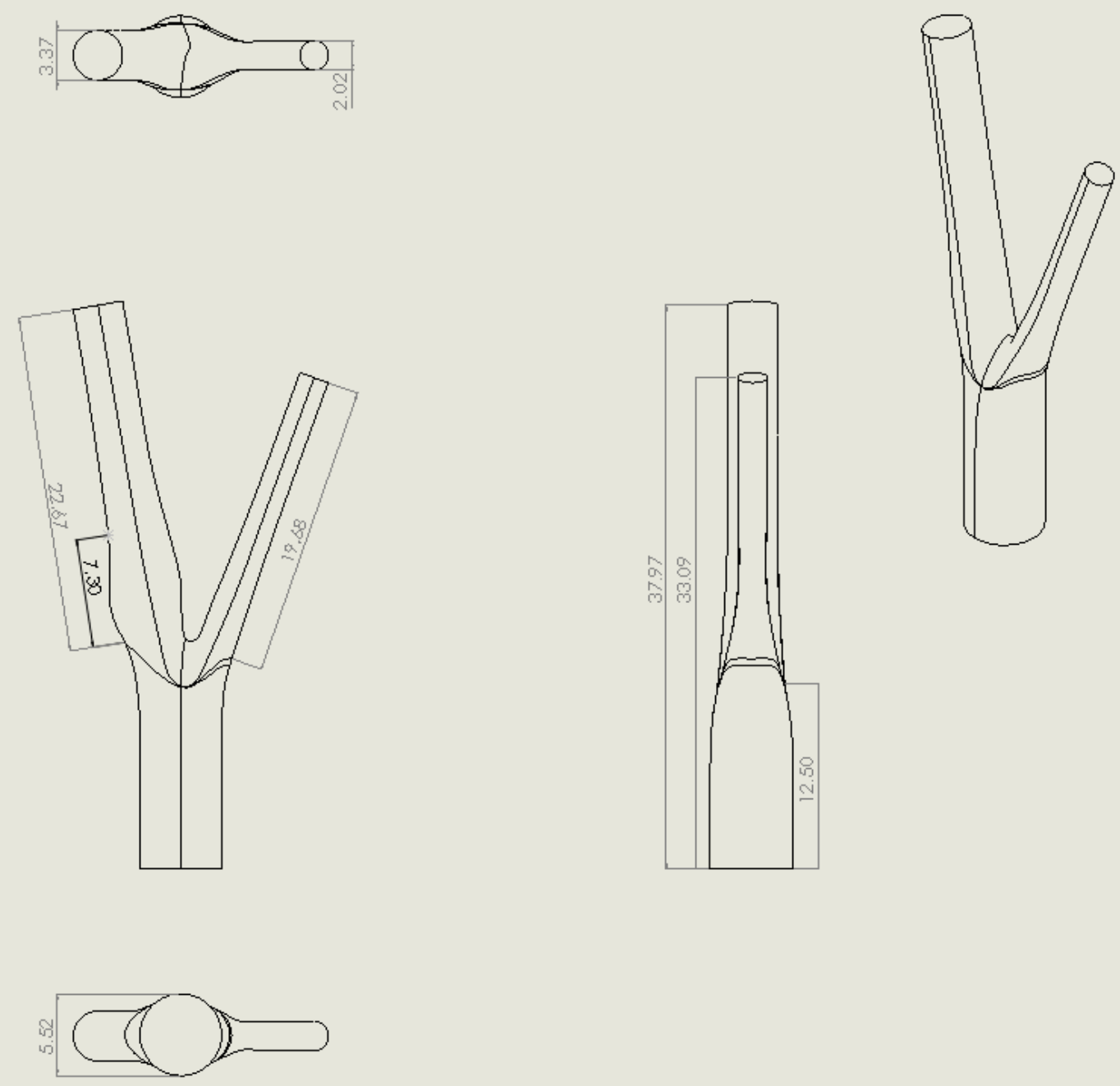

Figure 4.1: SolidWorks drawing including front, side, top, bottom, and orthogonal views of modeled geometry where all dimensions are in millimeters.

As shown above in Figure 4.1, the main vessel is the common carotid artery and the two daughter vessels are the internal and external carotid artery. The internal carotid artery has a larger diameter and contains the bulb while the external carotid artery has a smaller diameter. Note that the artery dimensions are $5.52 \mathrm{~mm}$ for the CCA diameter, $3.37 \mathrm{~mm}$ for the ICA diameter, $2.02 \mathrm{~mm}$ for the ECA diameter, $37.97 \mathrm{~mm}$ for the overall length, $22.67 \mathrm{~mm}$ for the ICA length, and $12.5 \mathrm{~mm}$ for the CCA length. These diameter dimensions are similar to the data from Table 4.1. 


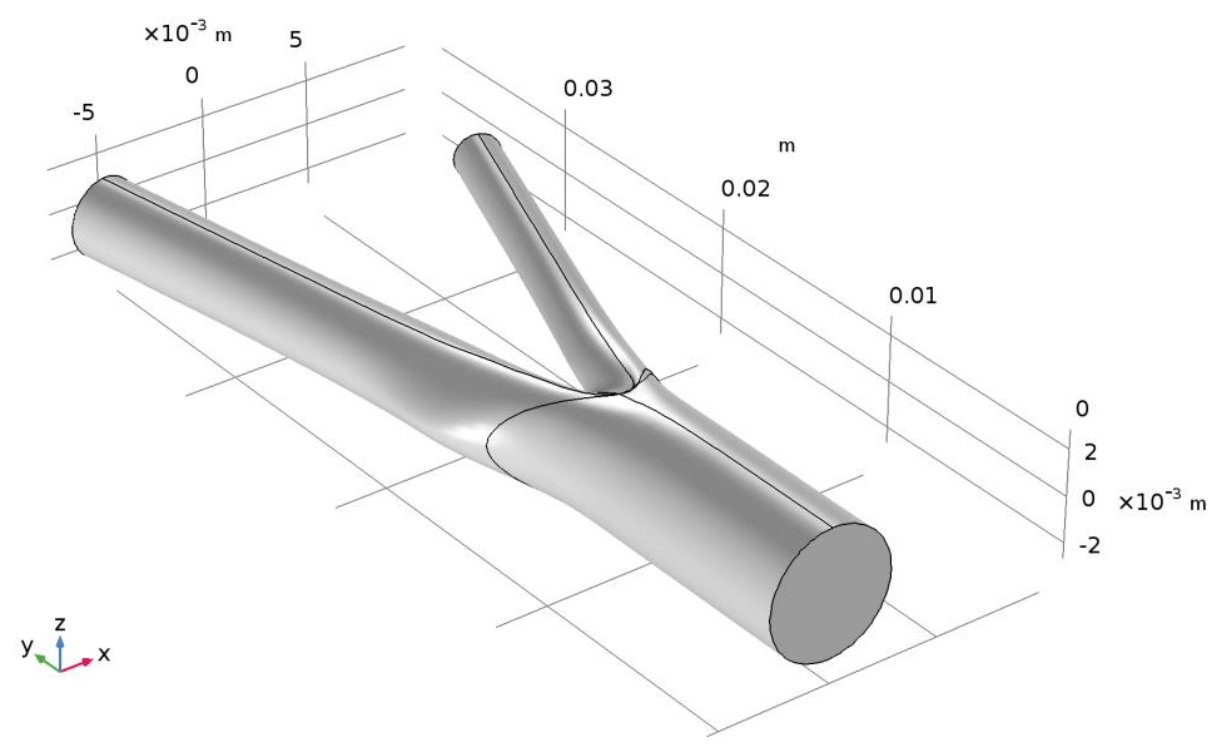

a

Figure 4.2: Carotid artery bifurcation 3D geometry represented in COMSOL

\section{Finite Element Analysis}

Meshing uses finite element analysis to discretize the model. The solution is obtained through stitching together low order polynomials over each element to form a piecewise global function. The three mesh considerations are how to divide the geometry, which shape should be used, and how to interpolate between the nodes. Because a 3D model was used, it was efficient to divide the model into quadrilateral geometries. The mesh was for fluid dynamics because near the wall, there are regions of turbulence in which COMSOL will make finer elements. 


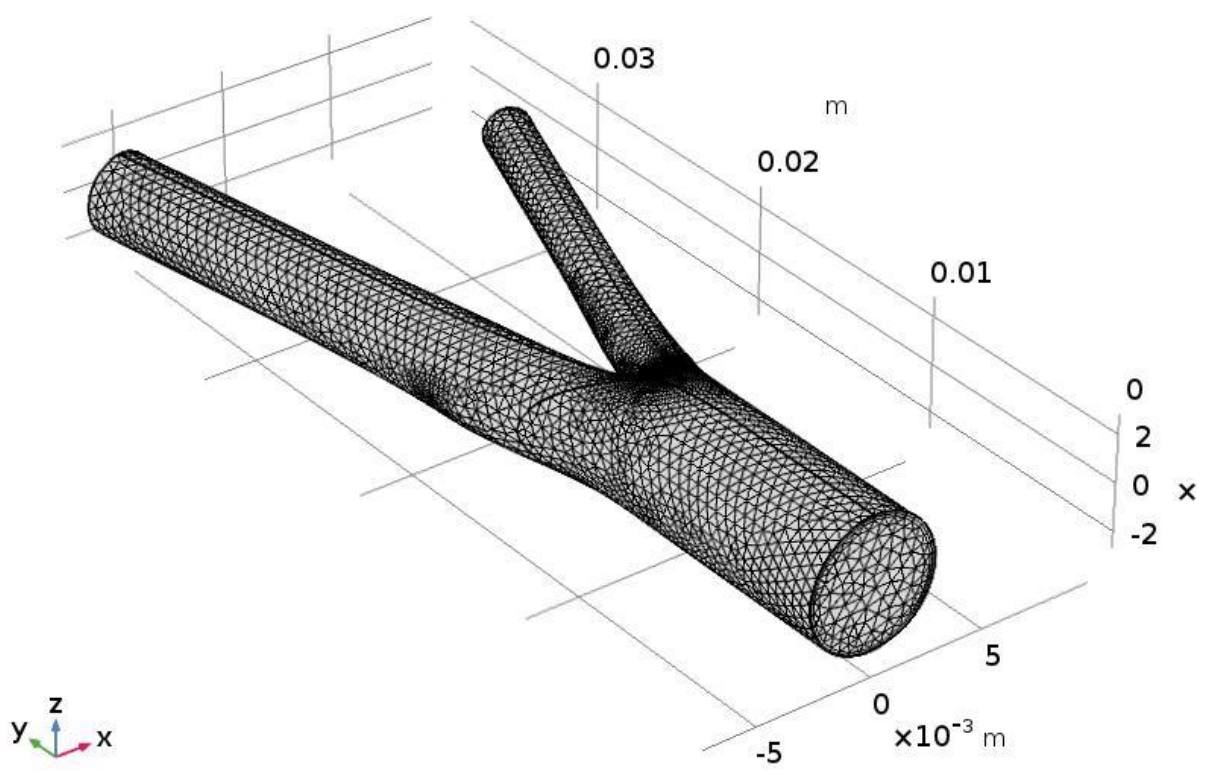

Figure 4.3: Finite element analysis using mesh represented. 3D meshed model in COMSOL using an extremely coarse tetrahedral mesh for fluid dynamics

The following table indicates the number of elements as well as the element shapes for the meshed model.

Table 4.2 Mesh Statistics

\begin{tabular}{|c|c|}
\hline mesh vertices & 31111 \\
\hline tetrahedral elements & 112268 \\
\hline prism elements & 19412 \\
\hline triangular elements & 10036 \\
\hline quadrilateral elements & 136 \\
\hline edge elements & 572 \\
\hline vertex elements & 15 \\
\hline number of elements & 131680 \\
\hline minimum element quality & 0.1183 \\
\hline average element quality & 0.6772 \\
\hline element volume ratio & $8.046 \times 10^{-5}$ \\
\hline mesh volume & $6.475 \times 10^{-7} \mathrm{~m}^{3}$ \\
\hline
\end{tabular}




\section{Chpater 5}

\section{TESTING, EVALUATION, AND DISCUSSION}

The volume inside the carotid artery where blood would normally flow was the region of interest for the simulation. COMSOL automatically defines the wall, endothelial lining, at the edges where a no slip condition was defined. Both laminar and turbulent flow included time dependency for $\mathrm{t}=$ 0-6 seconds with three 2 seconds time steps. COMSOL profile plots were given at $t=6$ seconds flow is fully developed.

Reynolds numbers were calculated using the cell Reynolds number feature in COMSOL for both 3D laminar and turbulent flow. A normalized value was evaluated on a unit scale which is comparable to the system Re as given in Eq. 3.5.

\section{COMSOL Profile Plots}

Slice plots were created to visualize how velocity, shear stress, shear rate, and Reynolds number change from the CCA to the ICA and ECA. A rainbow color scale was used where red indicates areas of higher magnitude and blue indicates areas of lower magnitude. 


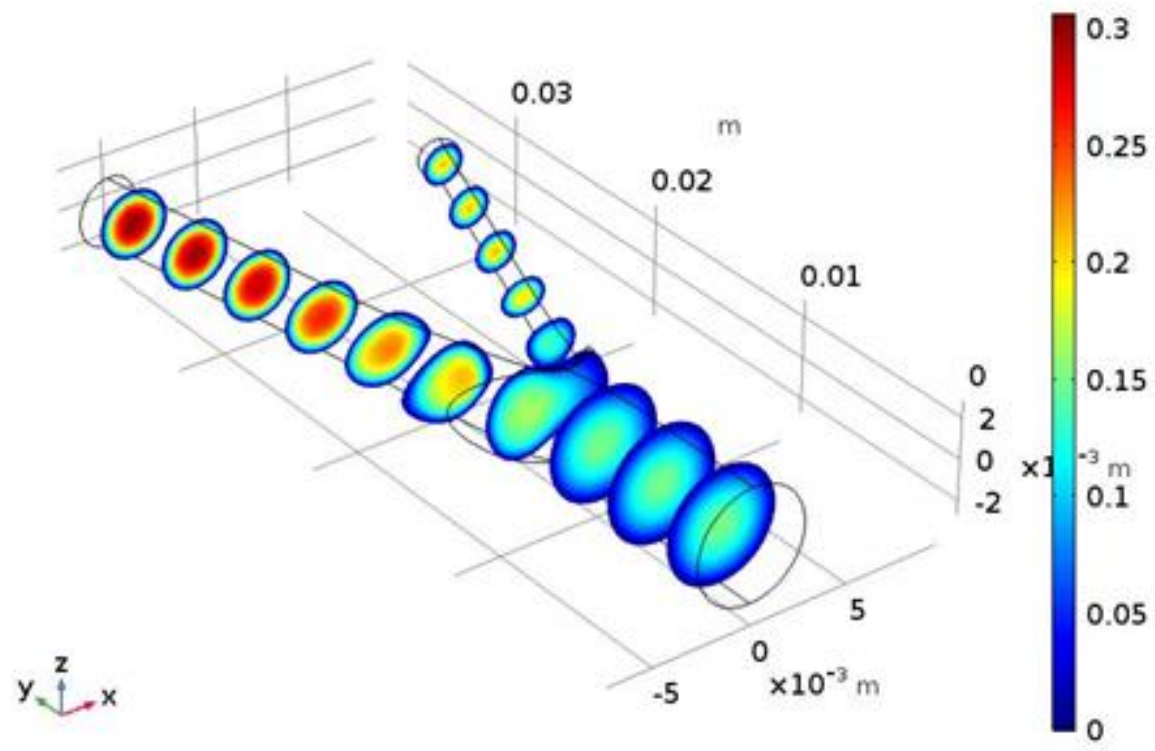

Time $=6 \mathrm{~s}$ Slice: Velocity magnitude $(\mathrm{m} / \mathrm{s})$

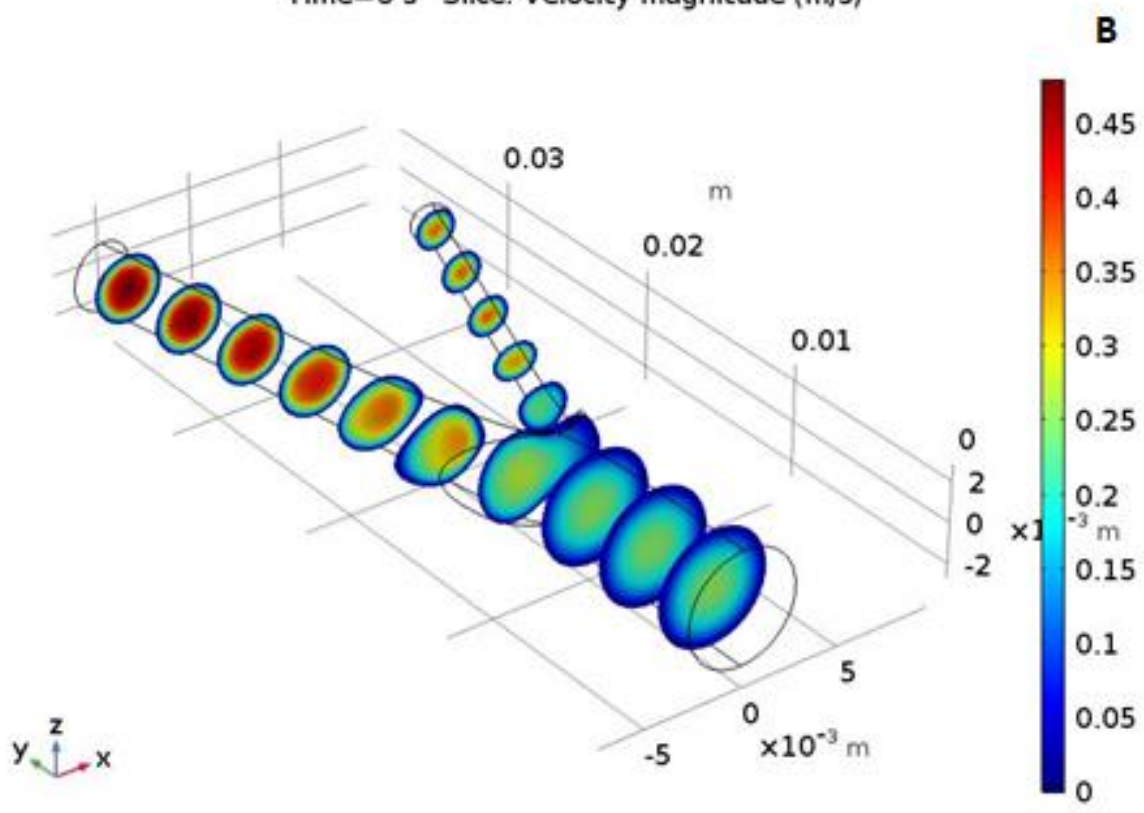

Figure 5.1 (A,B): X-Z sliced profile plots of velocity represented. A) laminar flow ranging from 0$30 \mathrm{~cm} / \mathrm{s} \mathrm{B}$ ) turbulent flow ranging from $0-45 \mathrm{~cm} / \mathrm{s}$ 


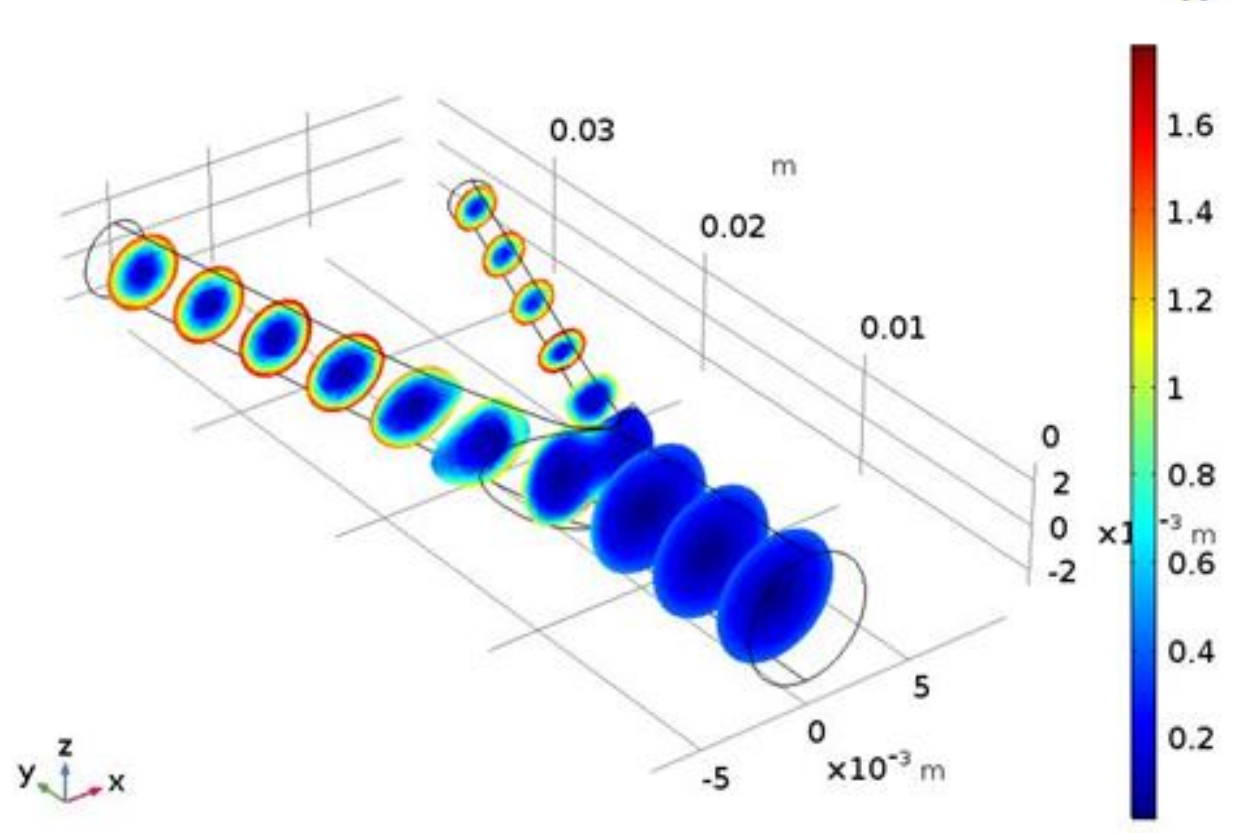

Time $=6 \mathrm{~s}$ Slice: Shear Stress $(\mathrm{Pa})$

B

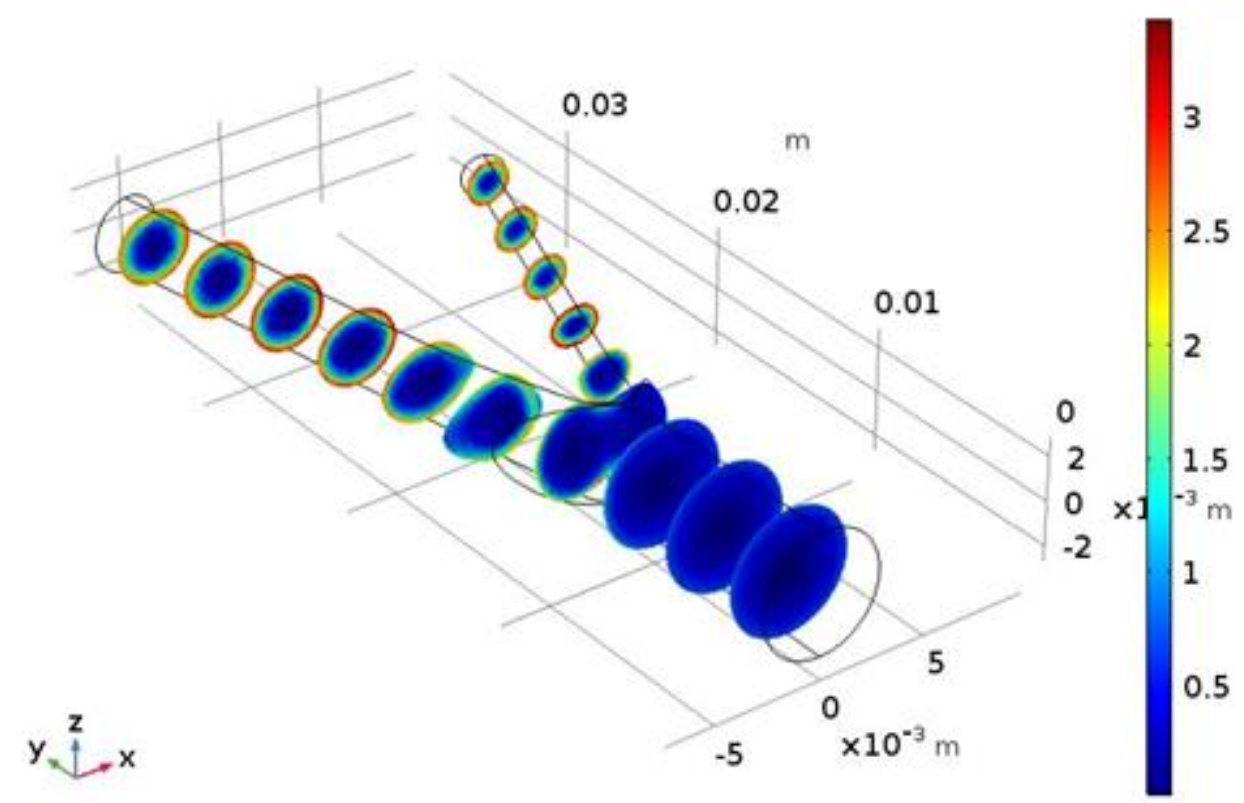

Figure 5.2 (A,B): X-Z sliced profile plots of shear stress represented. A) laminar flow ranging from 0.2-1.6 $\mathrm{Pa} \mathrm{B}$ ) turbulent flow ranging from $0.5-3 \mathrm{~Pa}$ 

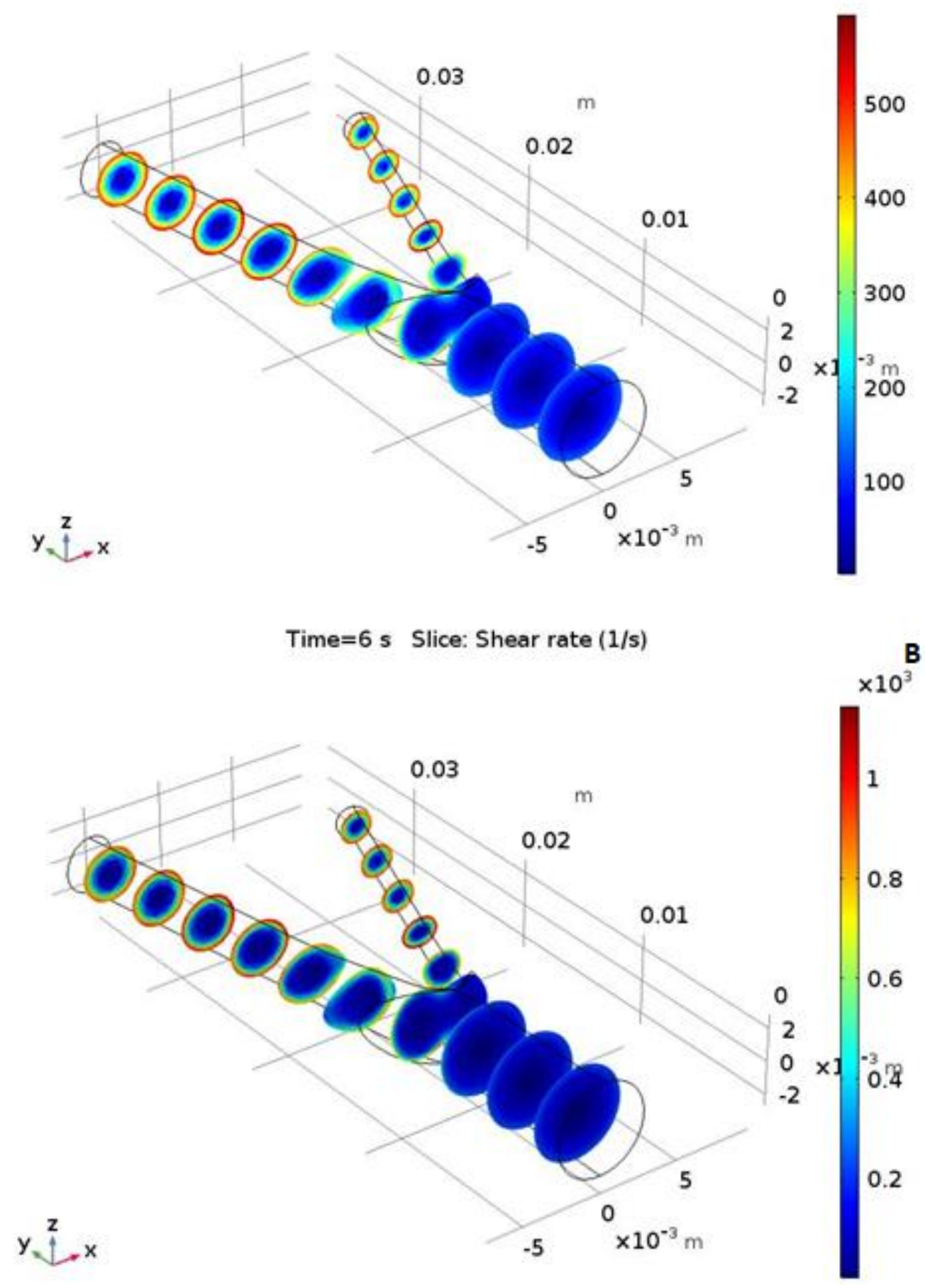

Figure 5.3 (A,B): X-Z sliced profile plots of shear rate represented. A) laminar flow ranging from $100-500(1 / \mathrm{s}) \mathrm{B})$ turbulent flow ranging from 200-1000 (1/s) 


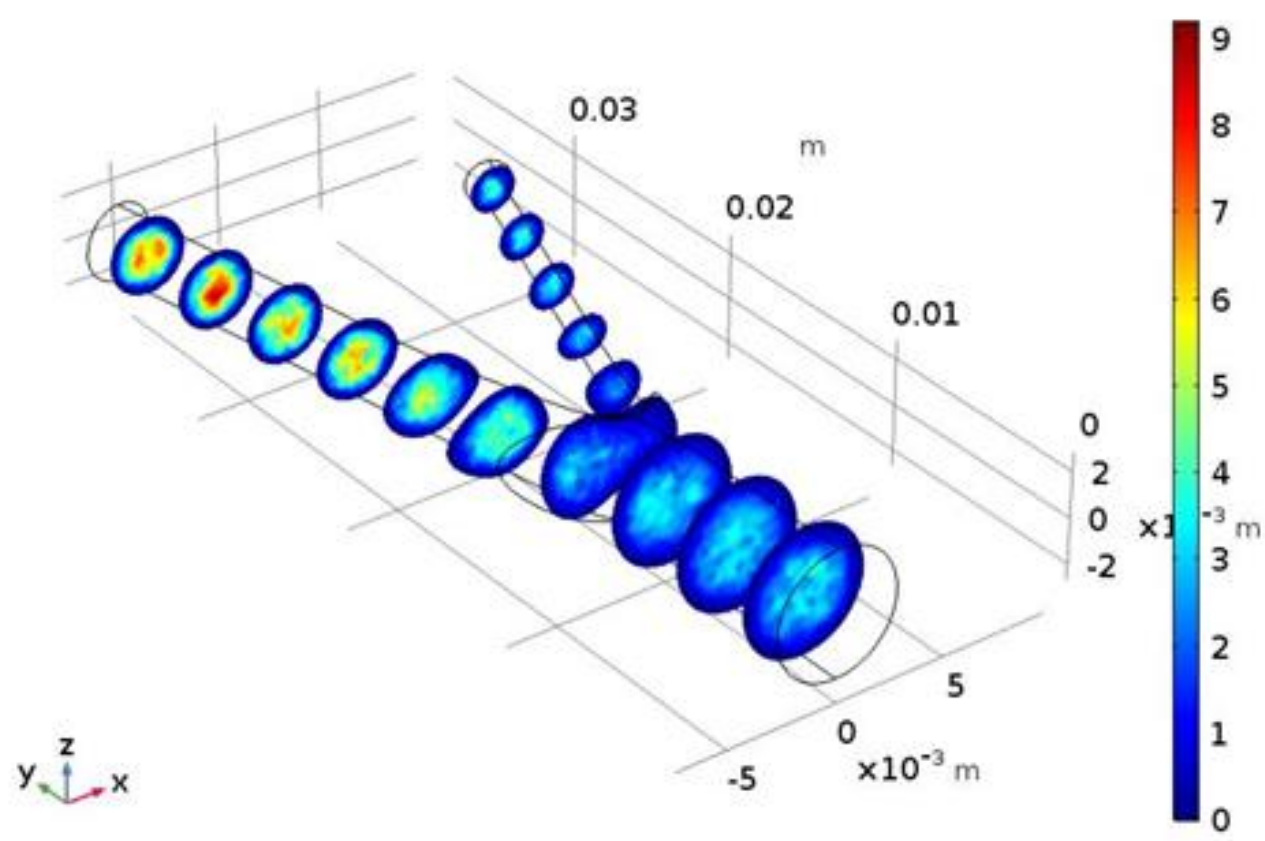

Time $=6$ s Slice: Cell Reynolds number (1)

B

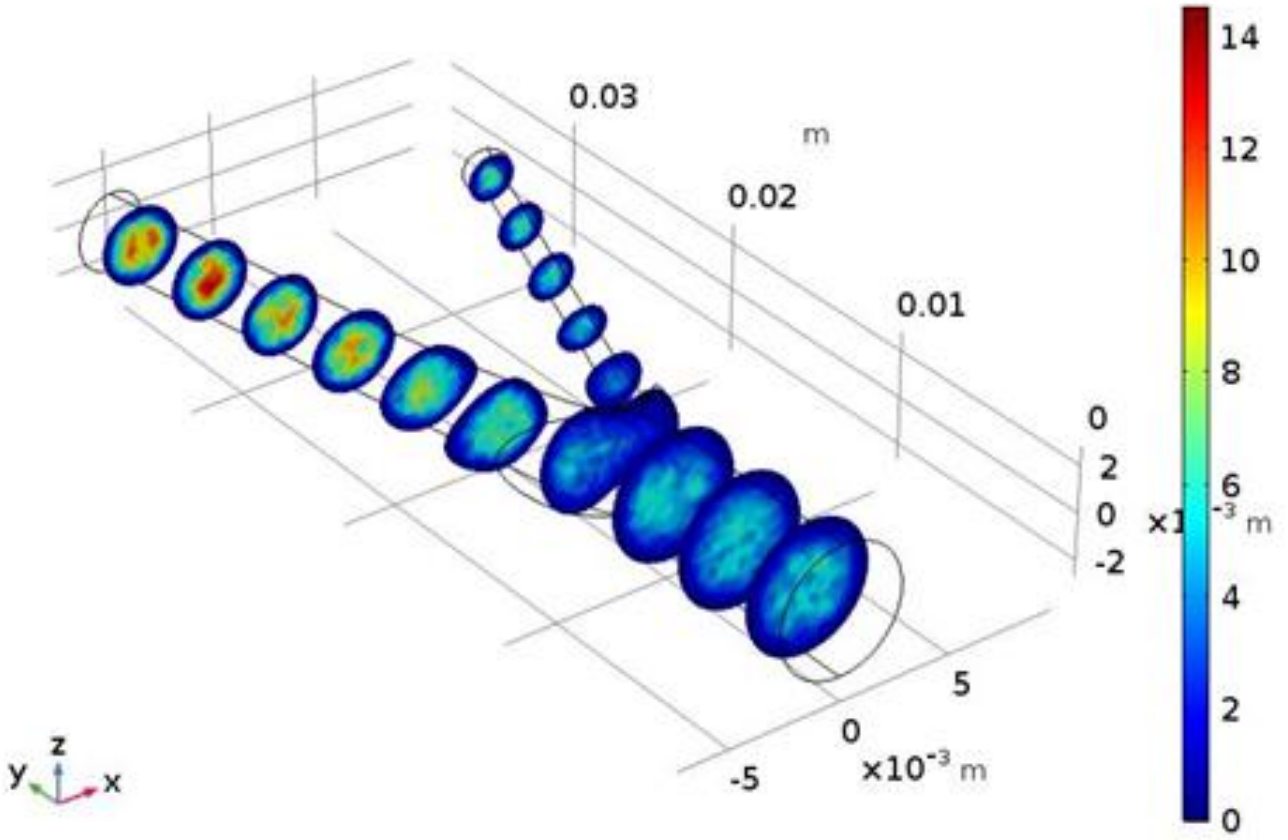

Figure 5.4 (A,B): X-Z sliced profile plots of cell Reynolds number represented. A) laminar flow ranging from 0-9 B) turbulent flow ranging from 0-14 
As shown by the profile plots, the turbulent flow profile had higher ranges than laminar flow for velocity, shear stress, shear rate, and Reynolds number. These results are consistent with the following data that was derived from a point evaluation using a 3D cut point.

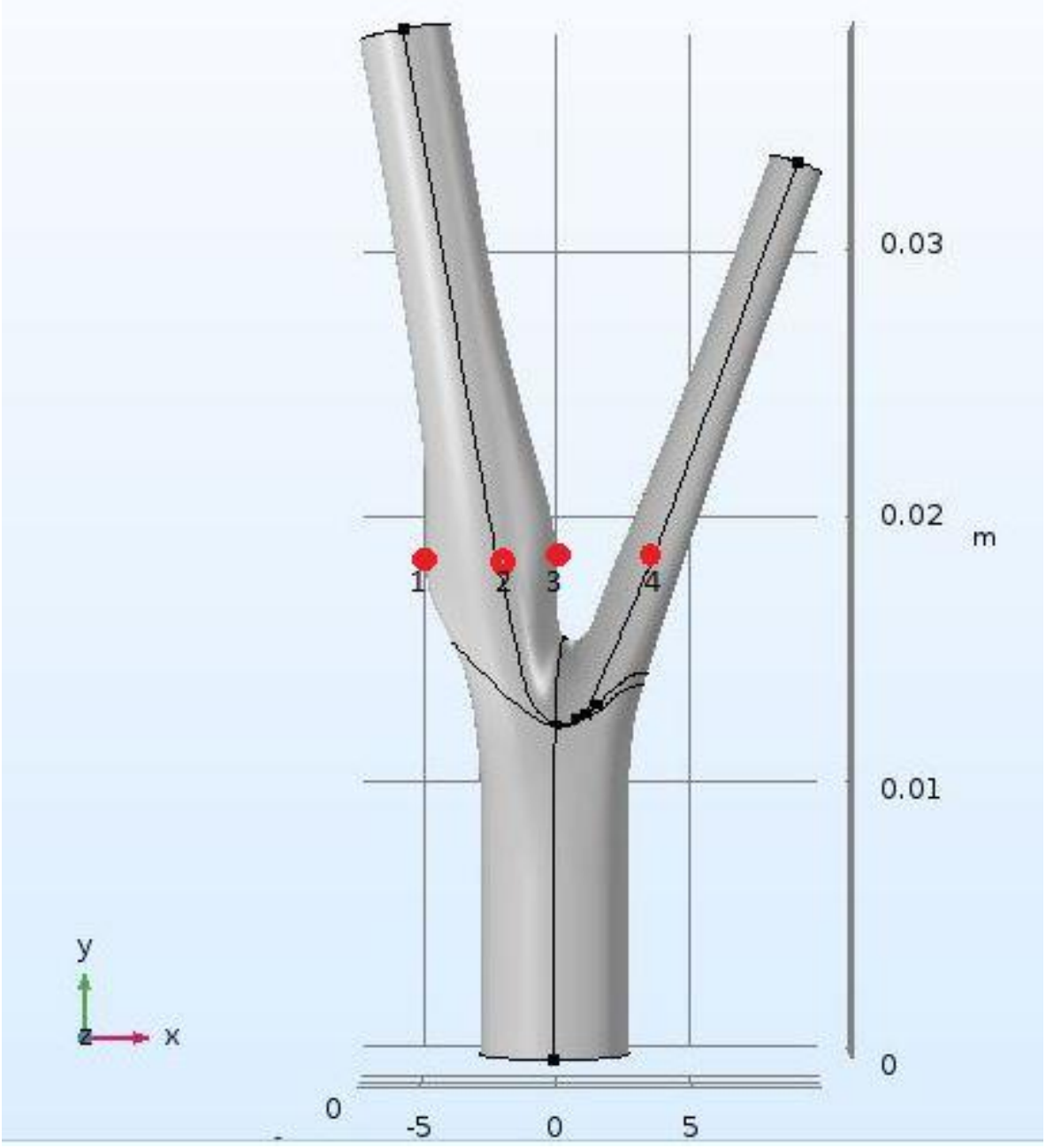

Figure 5.5: Cut points 1 and 3 taken at the carotid bulb wall of the ICA and cut points 2 and 4 taken at the centerline of the ICA and ECA respectively

Table 5.1 Turbulent flow shear stress and shear rate data

\begin{tabular}{|c|c|c|c|}
\hline Cut Point & Coordinates $\mathbf{( x , y , z )}$ & Shear Stress (Pa) & Shear Rate (1/s) \\
\hline 1 & $(-4.75 \mathrm{E}-3,0.0175,0)$ & 0.83056 & 276.7 \\
\hline 2 & $(-2 \mathrm{E}-3,0.0175,0)$ & 0.13915 & 46.382 \\
\hline 3 & $(-2 \mathrm{E}-5,0.0175,0)$ & 0.70733 & 235.78 \\
\hline 4 & $(3 \mathrm{E}-3,0.0175,0)$ & 0.21264 & 70.879 \\
\hline
\end{tabular}


The data below includes mass flow rate, shear rate, shear stress, and Cell Reynolds Number at the internal and external carotid artery centerlines i.e. cut points 2 and 4 . Data is similar for time points 2,4 , and 6 to show that flow is fully developed.

Table 5.2 Laminar Flow COMSOL Data

\begin{tabular}{|c|c|c|c|c|c|}
\hline $\begin{array}{c}\text { Time } \\
\text { (s) }\end{array}$ & $\begin{array}{l}\text { Location } \\
\text { (ICA/ECA) }\end{array}$ & $\begin{array}{c}\text { Mass Flow Rate } \\
(\mathrm{g} / \mathrm{s})\end{array}$ & $\begin{array}{c}\text { Shear Rate } \\
(1 / s)\end{array}$ & $\begin{array}{c}\text { Shear Stress } \\
(\mathrm{Pa})\end{array}$ & $\begin{array}{c}\text { Cell Reynolds } \\
\text { Number }\end{array}$ \\
\hline \multirow[t]{2}{*}{0} & ICA & $2.7077 \mathrm{E}-4$ & $2.2856 \mathrm{E}-3$ & 6.8567E-6 & $3.7923 E-4$ \\
\hline & ECA & $2.7077 \mathrm{E}-4$ & $6.5428 \mathrm{E}-3$ & $1.9628 \mathrm{E}-5$ & $2.6656 \mathrm{E}-4$ \\
\hline \multirow[t]{2}{*}{2} & ICA & 1.6801 & 26.108 & 0.078324 & 3.8039 \\
\hline & ECA & 1.6801 & 36.044 & 0.10813 & 1.4687 \\
\hline \multirow[t]{2}{*}{4} & ICA & 1.6554 & 25.090 & 0.075270 & 3.7468 \\
\hline & ECA & 1.6554 & 35.333 & 0.10600 & 1.4495 \\
\hline \multirow[t]{2}{*}{6} & ICA & 1.6572 & 25.222 & 0.075665 & 3.7513 \\
\hline & ECA & 1.6572 & 35.373 & 0.10612 & 1.4505 \\
\hline
\end{tabular}

Table 5.3 Turbulent Flow COMSOL Data

\begin{tabular}{|c|c|c|c|c|c|}
\hline $\begin{array}{c}\text { Time } \\
(\mathbf{s})\end{array}$ & $\begin{array}{l}\text { Location } \\
\text { (ICA/ECA) }\end{array}$ & $\begin{array}{c}\text { Mass Flow Rate } \\
(\mathrm{g} / \mathrm{s})\end{array}$ & $\begin{array}{c}\text { Shear Rate } \\
(1 / s)\end{array}$ & $\begin{array}{c}\text { Shear Stress } \\
(\mathrm{Pa})\end{array}$ & $\begin{array}{c}\text { Cell Reynolds } \\
\text { Number }\end{array}$ \\
\hline \multirow[t]{2}{*}{0} & ICA & $5.4155 \mathrm{E}-3$ & $4.5711 \mathrm{E}-3$ & 1.3713E-5 & 7.5846E-4 \\
\hline & ECA & $5.4155 \mathrm{E}-3$ & $1.3086 \mathrm{E}-2$ & $3.9257 \mathrm{E}-5$ & $5.3311 \mathrm{E}-4$ \\
\hline \multirow[t]{2}{*}{2} & ICA & 2.7781 & 46.303 & 0.13891 & 5.9621 \\
\hline & ECA & 2.7781 & 70.811 & 0.21243 & 2.4539 \\
\hline \multirow[t]{2}{*}{4} & ICA & 2.7811 & 46.381 & 0.13914 & 5.9684 \\
\hline & ECA & 2.7811 & 70.908 & 0.21273 & 2.4564 \\
\hline \multirow[t]{2}{*}{6} & ICA & 2.7796 & 46.382 & 0.13915 & 5.9655 \\
\hline & ECA & 2.7796 & 70.879 & 0.21264 & 2.4550 \\
\hline
\end{tabular}

Table 5.4 Data Summary at the ICA for $\mathrm{t}=6 \mathrm{~s}$

\begin{tabular}{|c|c|c|}
\hline & Shear Rate (1/s) & Shear Stress (mPa) \\
\hline Laminar Flow & 25.2 & 75.7 \\
\hline Turbulent Flow & 46.4 & 139 \\
\hline
\end{tabular}

The data compares to what is expected because turbulent flow resulted in greater shear rate and shear stress values than laminar flow at the centerline of the arterial model. This data is valuable in understanding that endothelial dysfunction inhibits vasodilation from lack of $\mathrm{NO}$, therefore increases velocity, and increases shear rate in diseased vessels. 


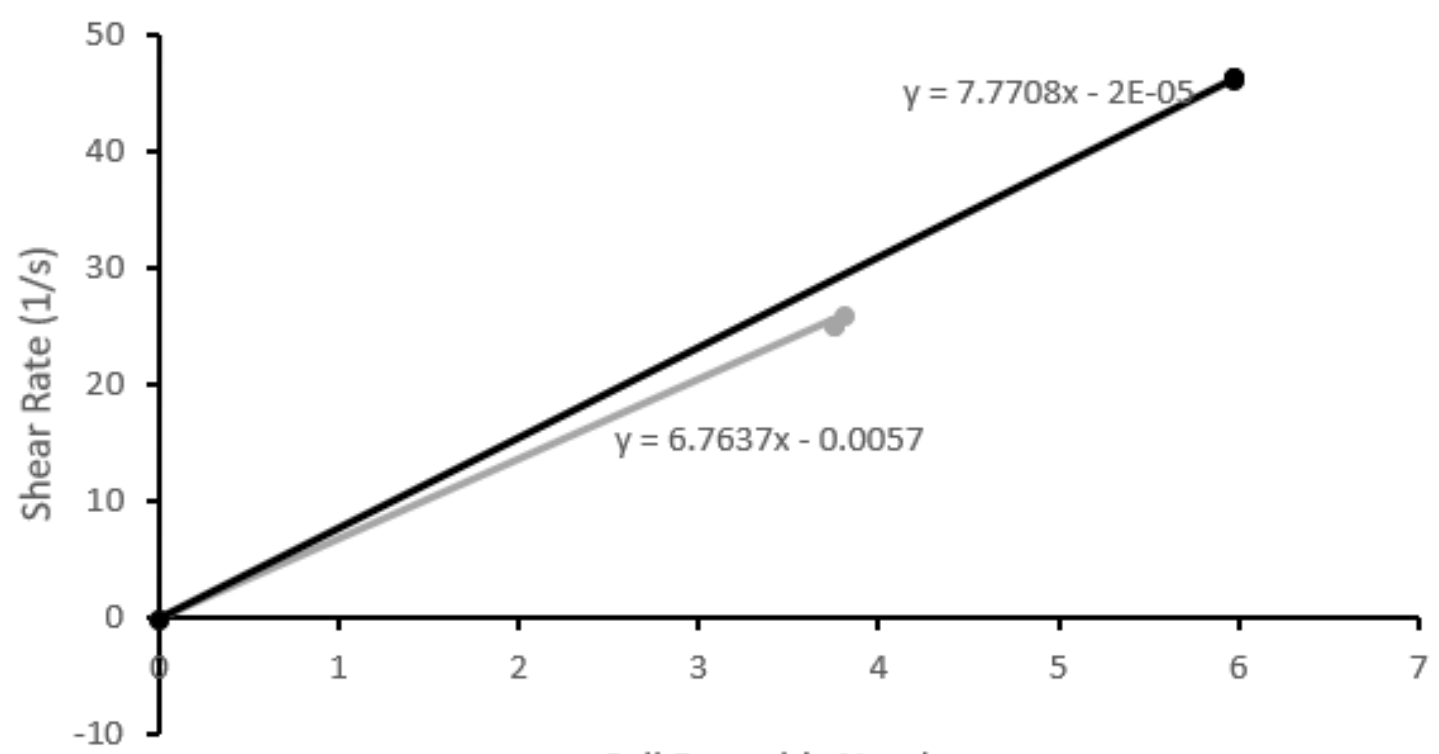

Cell Reynolds Number

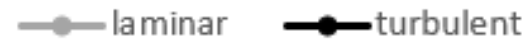

Figure 5.6: Shear Rate vs. Cell Reynolds Number

As shown in the above figure, shear rate is a function of Reynolds number. Turbulent flow has a slightly higher ratio of $\frac{\text { shear rate }}{\text { Reynolds \# }}$ than laminar flow.

As mentioned in Chapter 3, The Womersley Number $(\alpha)$ is a dimensionless number that relates pulsatile flow frequency to viscous effects. With the angular frequency, blood density, and blood viscosity staying constant, $\alpha$ is dependent on the vessel radius. Given that the ICA radius is 1.685 $\mathrm{mm}$, the angular frequency is $60 \mathrm{bpm}^{*}(2 \pi / 60) \mathrm{rad} / \mathrm{s}$, and $\rho$ and $\mu$ are the same constants given in Table 3.1, $\alpha=2.51$. The Womersley number calculated with this model is consistent with carotid artery values for $\alpha=2.21$. This is a good indication that the correct dimensions of the ICA arterial diameter were modeled. 
As shown in Table 5.4, shear rate values were 25.2 (1/s) for laminar flow and 46.4 (1/s) for turbulent flow. These results are consistent with a study done by Brooks et al ${ }^{33}$ in 1970 as shown in the following figure. Note that if shear rate were less than $5(1 / \mathrm{s})$, viscosity increases and blood behaves non-Newtonian.

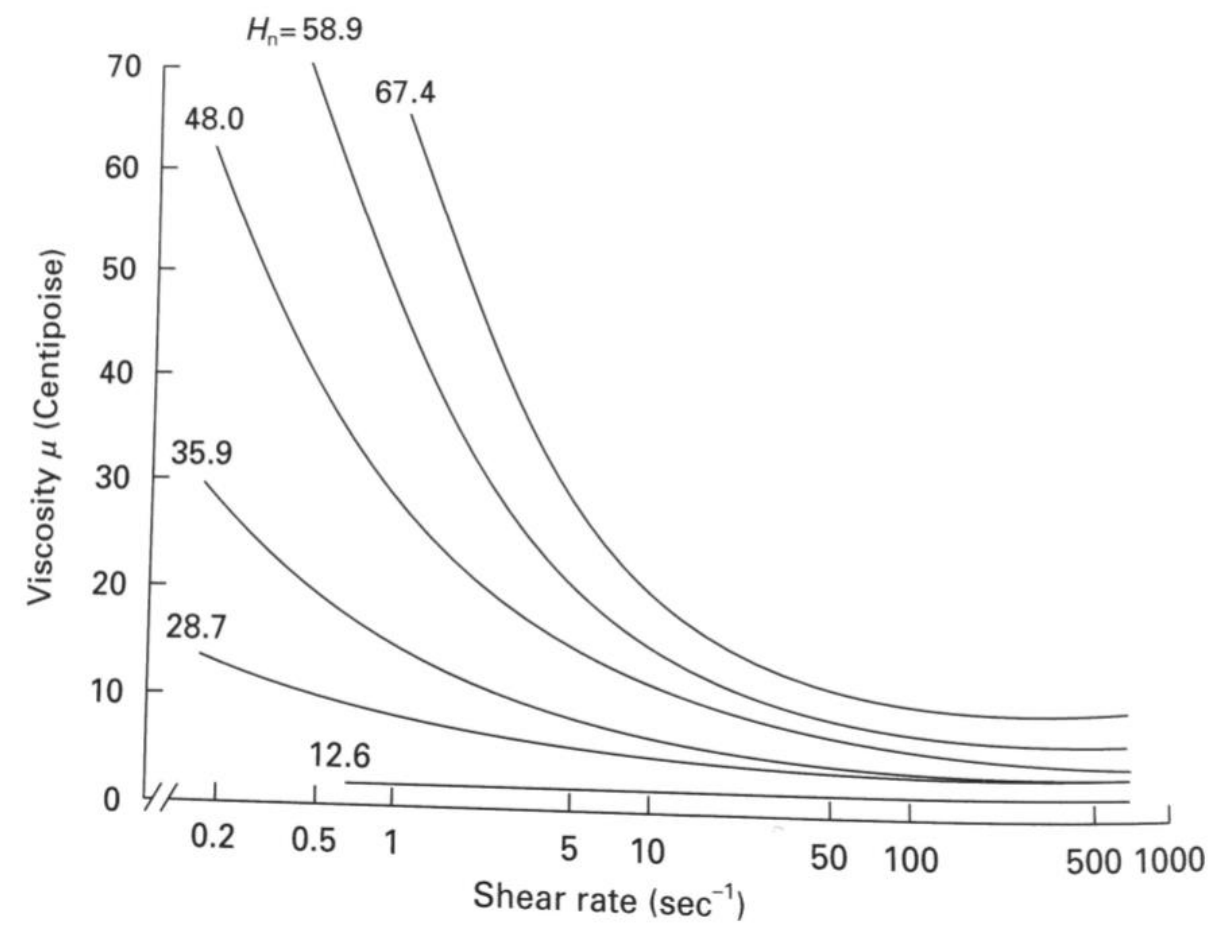

Figure 5.7: Viscosity vs. Shear Rate for various hematocrit percentages ${ }^{33}$ 
Chapter 6

\section{SUMMARY AND CONCLUSIONS}

\section{Contributions of this work to the field}

In this work, results of hemodynamics using a carotid artery model are presented. Wall shear stress and shear rate are investigated and compared for laminar and turbulent flow. It is wellestablished that regions of low wall shear stress are common sites for atherosclerotic plaque but through this work, the endothelial friction factor due to relative roughness can also cause atherosclerotic plaque. In doing so, laminar flow was dependent on Reynolds number only whereas turbulent flow was dependent on relative roughness as well as Reynolds number.

\section{Limitations/Strengths and Weaknesses of This Work}

One limitation of this work is that the arterial wall was a wall-free model, meaning that only the fluid flow through the artery was modeled and not the interaction between the wall and the fluid. There could have been different results if the biology of the wall, such as compliance and elastic modulus, were modeled. FEA was calculated using an extremely coarse mesh because of timing limitations with the modeling software. Data could have been slightly more accurate with a finer mesh, but it would have taken too long for COMSOL to compute the results. Another limitation is that the laminar and turbulent flow profile comparisons were made for only one healthy carotid artery geometry. To more accurately describe turbulent flow, small plaque deposits could have been implemented at the sinus of the ICA. Although plaque could have changed the turbulent model, the main takeaways are the differences in the overall shear rate and shear stress values comparing laminar and turbulent flow at the bifurcation. To simplify computations, Newtonian fluid was assumed even though blood has non-Newtonian properties.

A prominent strength of this work is that direct comparisons can be made regarding how shear rate and shear stress changes as the flow profile changes. Even though Reynolds number is a relative quantity, comparisons can still be made. This work provides an inexpensive and accessible way to analyze hemodynamics through the carotid artery without needing ICL. 


\section{Future Work}

For future studies, more biological factors should be considered to get as accurate results as possible. Compliance of the arterial wall, material properties of the artery, and non-Newtonian blood should be addressed in the model to evaluate the integrity of the data presented. It may be beneficial to 3D scan an excised artery to import a realistic geometry into SolidWorks to then perform computational fluid dynamics. Another possibility in the future is to compare results with clinical data. Patients who are at risk for atherosclerotic buildup can be included in the study to observe hemodynamics via imaging.

\section{Closing Statement}

In conclusion, the work presented shows that turbulent flow at the carotid bifurcation can cause an increase in friction factor and relative roughness that can ultimately lead to subclinical atherosclerosis. It is well known that regions of low wall shear stress are correlated with abnormal flow and endothelial dysfunction. These results, however, do not indicate exactly why or how relative roughness initiates in the endothelium. Since relative roughness creates a cascading effect leading to endothelial dysfunction, huge progress in stroke prevention can be made in understanding the root cause of relative roughness. Many researchers commonly describe the early stages of atherosclerosis as inflammation active $e^{7,10,13}$ due to a cytokine response. This response is hugely influenced by the oxidation of LDL molecules; therefore, a future hypothesis suggests that the over-activity ox-LDL uptake from macrophages is what ultimately causes the relative roughness and friction factor change. Ox-LDL is a molecule that has been researched for 30 years in its role for atherogenesis, but it is still unknown in terms of its definition and characterization $^{35}$. There is still work to be done to identify the biological cause of relative roughness of the endothelium to earlier detect and prevent MACE. Taking hemodynamic measurements of the carotid artery can open up a new way of approaching the cause of atherosclerotic plaque build-up and aid in stroke prevention. 


\section{REFERENCES}

${ }^{1}$ Heart Disease and Stroke Statistics 2017 At-a-Glance. American Heart Association.

${ }^{2}$ Tasneem Z. Naqvi, MD, FRCP, FACC, Fernando Mendoza, MD, Farhad Rafii, MD, Heidi Gransar, Maria Guerra, Norman Lepor, MD, FACC, FAHA, Daniel S. Berman, MD, FACC, FAHA, and Prediman K. Shah, MD, FACC, FAHA. High Prevalence of Ultrasound Detected Carotid Atherosclerosis in Subjects with Low Framingham Risk Score: Potential Implications for Screening for Subclinical Atherosclerosis. American Society of Echocardiography. 23: 809-815, 2010.

${ }^{3}$ Tasneem Z. Naqvi. Real Time Atherosclerosis Assessment in Outpatient Cardiology Practice Along With Cardiovascular Risk Assessment and Physician Patient Communication: A ThreePronged Approach for Patient Risk Evaluation, Education, and Treatment. American Society of Echocardiography. 28: 16A-17A

${ }^{4}$ Susanne Bartels, Angelica Ruiz Franco, Tatjana Rundek. Carotid Intima-Media Thickness (cIMT) and Plaque from Risk Assessment and Clinical Use to Genetic Discoveries. Elsevier Urban \& Fischer. 1: 139-145, 2012.

${ }^{5}$ Tasneem Z. Naqvi, Ming-Sum Lee. Carotid Intima-Media Thickness and Plaque in Cardiovascular Risk Assessment. JACC: Cardiovascular Imaging. 7, NO 10: 1025-38, 2014.

${ }^{6}$ Tasneem Z. Naqvi, MD. Quantifying Atherosclerosis by “3D” Ultrasound Works! American College of Cardiology. 65, NO 11: 1075-7, 2015.

${ }^{7}$ Morteza Naghavi, MD, Erling Falk, MD, PhD, Harvey S. Hecht, MD, Michael J. Jamieson, MD, Sanjay Kaul, MD, Daniel Berman, MD, Zahi Fayad, PhD, Matthew J. Budoff, MD, John Rumberger, MD, PhD, Tasneem Z. Naqvi, MD, Leslee J. Shaw, PhD, Ole Faergeman, MD, Jay Cohn, MD, Raymond Bahr, MD, Wolfgang Koenig, MD, PhD, Jasenka Demirovic, MD, PhD, Dan Arking, PhD, Victoria L. M. Herrera, MD, Juan Badimon, PhD, James A. Goldstein, MD, Yoram Rudy, PhD, Juhani Airaksinen, MD, Robert S. Schwartz, MD, Ward A. Riley, PhD, Robert A. Mendes, MD, Pamela Douglas, MD, and Prediman K. Shah, MD. From Vulnerable Plaque to Vulnerable Patient-Part III: Executive Summary of the Screening for Heart Attack Prevention and Education (SHAPE) Task Force Report. American Journal of Cardiology. 98: 2H-15H, 2006.

${ }^{8}$ Bonetti PO, Lerman LO, Lerman A. Endothelial dysfunction: a marker of atherosclerotic risk. Arterioscler Thromb Vasc Biol. 23 NO 2: 168-75, 2003.

9Widlansky ME, Gokce N, Keaney JF Jr, Vita JA. The Clinical Implications of Endothelial Dysfunction. JACC. 42 NO 7: 1149-60, 2003.

${ }^{10}$ Scott Kinlay MB BS, PhD, Peter Ganz MD. Role of Endothelial Dysfunction in Coronary Artery Disease and Implications for Therapy. American Journal of Cardiology. 80: 11I-16I, 1997.

${ }^{11}$ Markus Juonala, MD; Jorma S.A. Viikari, MD, PhD; Tomi Laitinen, MD, PhD; Jukka Marniemi, PhD; Hans Helenius, MSc; Tapani Rönnemaa, MD, PhD; Olli T. Raitakari, MD, PhD. Interrelations Between Brachial Endothelial Function and Carotid Intima-Media Thickness in Young Adults. Circulation. 110: 2918-23, 2004.

${ }^{12}$ Lerman A, Burnett JC Jr. Intact and Altered Endothelium in Regulation of Vasomotion. Circulation. 86: 12-19, 1992.

${ }^{13}$ Peter Ganz, Joseph A. Vita. Testing Endothelial Vasomotor Function. Circulation. 108: 2049-53, 2003.

${ }^{14}$ Mary C. Corretti, MD, Todd J. Anderson, MD, Emelia J. Benjamin, MD, David Celermajer, MD, Francois Charbonneau, MD, Mark A. Creager, MD, John Deanfield, MD, Helmut Drexler, MD, Marie Gerhard-Herman, MD, David Herrington, MD, Patrick Vallance, MD, Joseph Vita, MD, Robert Vogel, MD. Guidelines for the Ultrasound Assessment of Endothelial-Dependent Flow-Mediated Vasodilation of the Brachial Artery. JACC. 39 NO 2: 257-65, 2002. 
${ }^{15}$ Vaidehi Sheth and Arthur Ritter, PhD. Using Computational Fluid Dynamics Model to Predict Changes in Velocity properties in Stented Carotid Artery. Stevens Institute of Technology, Department of Biomedical Engineering. 2010.

${ }^{16}$ Agostino Gnasso, Claudio Carallo, Concetta Irace, Vitaliano Spagnuolo, Giuseppina De Novara, Pier Luigi Mattioli, Arturo Pujia. Association Between Intima-Media Thickness and Wall Shear Stress in Common Carotid Arteries in Healthy Male Subjects. Circulation. 94: 3257-62, 1996.

${ }^{17}$ G.J. Langewouters, K.H. Wesseling, W.J.A Goedhard. The static elastic properties of 45 human thoracic and 20 abdominal aortas in vitro and the parameters of a new model. Elsevier. 17: 425435, 1984.

${ }^{18}$ Stephanie Laurent, John Cockcroft, Luc Van Bortel, Pierre Boutouyrie, Cristina Giannattasio, Daniel Hayoz, Bruno Pannier, Charalambos Vlachopoulos, Ian Wilkinson, Harry Struijker-Boudier. Expert Consensus Document on Arterial Stiffness: Methodological Issues and Clinical Applications. European Heart Journal. 27: 2588-2605, 2006.

${ }^{19}$ Carmel M. McEniery, Sharon Wallace, Isla S. Mackenzie, Barry McDonnell, Yasmin, David E. Newby, John R. Cockcroft, Ian B. Wilkinson. Endothelial Function Is Associated with Pulse Pressure, Pulse Wave Velocity, and Augmentation Index in Healthy Humans. Hypertension: AHA. 48:602-8, 2006.

${ }^{20}$ Tania Pereira, Carlos Correia, Joao Cardoso. Novel Methods for Pulse Wave Velocity Measurement. Journal of Medical and Biological Engineering. 35: 555-65, 2015.

${ }^{21} \mathrm{~J}$. Crighton Bramwell, A.V. Hill. The Velocity of the Pulse Wave in Man. The Royal Society Publishing. 1922.

${ }^{22}$ Hyun Woong Park, Ki-Hong Kim, In Girl Song, Taek-Geun Kwon, Wan Ho Kim, Jang-Ho Bae. Body mass index, carotid plaque, and clinical outcomes in patients with coronary artery disease. Wolters Kluwer Health. 28 NO 4: 278-286, 2017.

${ }^{23}$ Michael E. Aldridge, MD, Khuyen Do, MD, Thiri Oo, MD, and Tasneem Z. Naqvi, MD. Carotid Intima-Media Thickness and Plaque Assessment by Trained Medical Residents: Validation and Preliminary Testing of a Training Protocol. American Society of Echocardiography. 26, NO 12: 1457-64, 2013.

${ }^{24}$ Mary J Roman, Tasneem Z Naqvi, Julius M Gardin, Marie Gerhard-Herman, Michael Jaff and Emile Mohler. Clinical application of noninvasive vascular ultrasound in cardiovascular risk stratification: a report from the American Society of Echocardiography and the Society for Vascular Medicine and Biology. American Society of Echocardiography. 11: 201-211, 2006.

25 Virchow's Triad Medicine Hack, 2011.

${ }^{26}$ Samuel E Logan. On the Fluid Mechanics of Human Coronary Artery Stenosis. IEEE Transactions on Biomedical Engineering. 22(4), July 1975.

${ }^{27}$ Stephan Whitaker. Levels of Simplification: The Use of Assumptions, Restrictions, and Constraints in Engineering Analysis. Chemical Engineering Division ASEE. 1988.

${ }^{28}$ Flow in Pipes: Fluid Mechanics. University of Oslo. 321-343, 2004.

${ }^{29}$ Martin Reriani, Jaskanwal Sara, Andreas Flammer, Rajiv Gulati, Jing Li, Charanjit Rihal, Ryan Lennon, Lilach Lerman, Amir Lerman. Coronary endothelial function testing provides superior discrimination compared to standard clinical risk scoring in prediction of cardiovascular events. Coronary Artery Disease, 27(3), 213-220.

${ }^{30}$ Jose Coelho Neto, Ubirajara Agero, Ricardo T. Gazzinelli, Oscar N. Mesquita. Measuring Optical and Mechanical Properties of a Living Cell with Defocusing Microscopy. Biophysical Journal. 91(3), 1108-1115, August 2006.

${ }^{31}$ Gregoratos, Gabriel, et al. ACC/AHA Guidelines for Implantation of Cardiac Pacemakers and Antiarrhythmia Devices: Executive Summary. Circulation, American Heart Association, Inc., 97, 1325-1335, 1998. 
${ }^{32}$ Ronen Rubinshtein, Jeffrey T. Kuvin, Morgan Soffler, Ryan J. Lennon, Shahar Lavi, Rebecca E. Nelson, Geralyn M. Pumper, Lilach O. Lerman, Amir Lerman. Assessment of Endothelial

Function by Non-Invasive Peripheral Arterial Tonometry Predicts Late Cardiovascular Adverse

Events, European Heart Journal. 31(9),1142-1148, May 2010.

${ }^{33}$ Wilmer Nichols, Michael O'Rourke. McDonald's Blood Flow in Arteries: Theoretical, Experimental, and Clinical Principles, Arnold. Fourth Edition, 1960.

34Fluid Flow Viscosity Neutrium, 2012.

${ }^{35}$ Parthasarathy, S., Raghavamenon, A., Garelnabi, M. O., \& Santanam, N. Oxidized Low-Density Lipoprotein. Methods in Molecular Biology, 610, 403-417, 2010.

${ }^{36} \mathrm{LDL}$ Oxidation in Atherogenesis, Qiagen.

${ }^{37}$ Blasius, P. R. H. Das Aehnlichkeitsgesetz bei Reibungsvorgangen in Flüssigkeiten.

Forschungsheft 131, 1-41, 1913.

38Jaroslaw Krejza, Michal Arkuszewski, Scott E. Kasner, John Weigele, Andrzej Ustymowicz, Robert W. Hurst, Brett L. Cucchiara and Steven R. Messe. Carotid Artery Diameter in Men and Women and the Relation to Body Neck Size, Stroke. 37:1103-1105, March 27, 2006

${ }^{39}$ Adrian J. Y. Chee, Chung Kit Ho, Billy Y. S. Yiu, and Alfred C. H. Yu. Walled Carotid Bifurcation Phantoms for Imaging Investigations of Vessel Wall Motion and Blood Flow Dynamics, IEEE Transactions on Ultrasonics, Ferroelectrics, and Frequency Control, vol. 63, no. 11, November 2016. 


\section{APPENDIX A}

Table A.1 Friction factor and relative roughness data calculated from previous experiments (see section 2.6) for turbulent flow

\begin{tabular}{|c|c|c|c|}
\hline & $\begin{array}{c}\text { Friction Factor } \\
\text { (unitless) }\end{array}$ & $\begin{array}{c}\text { Relative Roughness } \\
\text { (unitless) }\end{array}$ & ff/rr ratio \\
\hline Turbulent Flow & 1.61 & 0.26 & 6.19 \\
\hline
\end{tabular}




\section{APPENDIX B}

Womersley Number Calculation

$$
\begin{aligned}
\alpha & =r \sqrt{\frac{\omega \rho}{\mu}} \\
\alpha=(1.685 E-3 \mathrm{~m}) & \sqrt{\frac{60\left(\frac{\pi}{30} \mathrm{rad} / \mathrm{s}\right)\left(1060 \frac{\mathrm{kg}}{\mathrm{m}^{3}}\right)}{0.003 \mathrm{~Pa} * \mathrm{~s}}} \\
\alpha & =2.51
\end{aligned}
$$

